\title{
What inflation measure should a currency union target?
}

\author{
William A. Barnett \\ Department of Economics \\ University of Kansas \\ Lawrence, USA \\ and \\ Center for Financial Stability \\ New York, NY, USA \\ williamabarnett@gmail.com \\ Chan Wang \\ School of Finance \\ Central University of Finance and Economics \\ Beijing, China \\ wangchanist@126.com \\ Xue Wang \\ Department of Finance \\ Jinan University \\ Guangzhou, China \\ wangxue1207@hotmail.com \\ Liyuan $\mathrm{Wu}^{*}$ \\ Guanghua School of Management \\ Peking University \\ Beijing, China \\ wuly@pku.edu.cn
}

May 25, 2018

\begin{abstract}
What is the appropriate inflation target for a currency union, when conducting monetary policy: core inflation or headline inflation? We answer the question in a two-country New Keynesian model with an energy sector. We derive the welfare loss function and find that optimal monetary policy should target output gaps, the terms of trade gap, the Prouder Price Index inflation rates, and the real marginal cost gaps. We use the welfare loss function to evaluate two alternative Taylor-type monetary policy rules. We find that the choice of preferred policy rule depends on the shocks. Specifically, when productivity shocks hit the economy, the policymaker should follow the headline inflation Taylor rule, while the core inflation Taylor rule should be followed when a negative energy endowment shock hits the economy.
\end{abstract}

Key words: Core inflation; Headline inflation; Optimal monetary policy; Currency union; Welfare.

JEL: E5; F3; F4

*Corresponding author. 


\section{Introduction}

Recently, substantial volatility in energy prices has motivated debate about how monetary policymakers should conduct monetary policy. As is well known, considerable energy price hikes produce a stark distinction between headline and core inflation rates. Headline inflation measurement is similar to that from the conventional consumer price index (CPI), while core inflation removes some of the CPI's most volatile components, such as energy and food prices. Which inflation rate is the appropriate target for monetary policy? Opinions among researchers and policymakers are divided on this subject. Energy price hikes can produce a phenomenon resembling bifurcation in New Keynesian model dynamics, thereby altering the optimal policy regime. On the general subject of bifurcation of New Keynesian models, see Barnett and Duzhak (2010). ${ }^{1}$

Researchers have long considered core inflation to be the most appropriate measure of inflation for targeting by monetary policymakers. In a New Keynesian monetary model, Aoki (2001) demonstrates that targeting sticky-price inflation can achieve stabilization of relative price around its efficient value, as is one of the appropriate goals of monetary policy. Aoki (2001) thereby provides a rationale for targeting the core inflation rate. Aoki’s (2001) conclusion is confirmed by Mankiw and Reis (2003). In a multi-sector model, they show that the monetary policymaker should put more weight on sectors that have sluggish price adjustment. Bodenstein et al. (2008) also find that, for both the operational conduct of monetary policymakers and their communication strategies, monetary policy responding to a forecast of core inflation performs best to stabilize the economy. By contrast, Anand et al. (2015) find that, for developing countries with incomplete financial markets, targeting the core inflation rate cannot stabilize output and improve welfare. In this circumstance, targeting the headline inflation rate will improve welfare. In practice, when framing the objectives and

\footnotetext{
${ }^{1}$ Strictly speaking, Barnett and Duzhak (2010) explore the literal concept of bifurcation, by which the parameters of a New Keynesian model move, while crossing a Hopf or period-doubling bifurcation boundary. Changes in variables do not cause bifurcations in the formal mathematical sense.
} 
conducting monetary policy, both the Bank of England and the European Central Bank target the headline inflation rate. However, other central banks, including the U.S. Federal Reserve, pay more attention to the core inflation rate, at least in describing their operational decisions.

Since the European Central Bank targets the headline inflation rate, one question naturally arises: is it always an optimal choice for European Central Bank to target the headline inflation rate? Relevant multilateral aggregation theory for aggregation within and over currency unions can be found in Barnett (2007). ${ }^{2}$ Benigno (2004) aims at examining how to conduct optimal monetary policy for a two-country currency union. He finds that, when two countries have the same degree of price stickiness, it is optimal for the monetary policymaker to target a weighted average of the inflation rates in the union, with the weights being equal to the sizes of the countries. Though he makes substantial progress towards answering the question facing the European Central Bank, he makes no distinction between the core inflation rate and the headline inflation rate. Thus, the conclusion obtained in Benigno (2004) cannot act as a clear rationale to guide the monetary policy choice facing the European Central Bank.

To fill the gap, building on Benigno (2004), we distinguish the core inflation rate from the headline inflation rate by introducing a flexible-price energy good into consumption and production. We then investigate which inflation rate performs better from the perspective of welfare loss. We find that the "divine coincidence" breaks down. When the monetary policymaker chooses to target zero inflation rate for the whole union, it becomes impossible to close output gaps simultaneously. The reason is that the terms of trade cannot adjust efficiently in response to asymmetric shocks, .

Following the literature, we derive the welfare loss function of the monetary policymaker in the union and find that the welfare loss function depends upon the inflation rates of the non-energy consumption goods in both countries, the union-wide output gap, the terms of trade gap, and the real marginal cost gaps. It is well known that

\footnotetext{
2 Barnett (2007) proved that in a currency union, there are two cost of living indexes, needed for different purposes, as the "headline” price aggregate. In that paper, see Definition 3, Lemma 3, and the discussion following Lemma 3. In this paper, our measurement of headline inflation is described in section 4.2 below.
} 
the output gap and the inflation rates of the sticky-price sectors are the sources of distortion in a standard New Keynesian monetary model. As mentioned previously, in a two-country currency union model, following asymmetric shocks, the terms of trade cannot adjust efficiently and thus cause the welfare loss. In our model, when energygood price is flexible, the price stickiness not only prevents energy good from being allocated efficiently between households and firms but also between firms in different countries. Accordingly, the real marginal cost gaps result in welfare loss.

We use the welfare loss function to evaluate two different Taylor-type monetary policy rules to answer the following question. In a currency union, what is the appropriate target for the monetary policymaker, the core inflation rate or the headline inflation rate? In one case, the interest rate is used to target the headline inflation rate. We call that policy the headline inflation Taylor rule (HIT). In the other case, the interest rate is used to target the core inflation rate. We call that policy the core inflation Taylor rule (CIT).

We find that which monetary policy rule performs best depends on the source of the shocks. Specifically, when the whole union is buffeted by productivity shocks, use of the CIT, rather than the HIT, causes the shocks to be amplified, producing increased welfare loss. In that circumstance, the European Central Bank's approach makes the correct choice, improving union-wide welfare, by targeting headline inflation. However, when a negative energy endowment shock hits the economy, the HIT amplifies the shock, leading to greater welfare loss. In that case, the European Central Bank could obtain welfare gain by following the CIT.

The rest of the paper is organized as follows. Section 2 lays out the model. Section 3 derives the steady state, the flexible-price equilibrium, and the sticky-price equilibrium. Section 4 performs the monetary policy analysis. Section 5 concludes.

\section{The model}

The currency union consists of two countries indexed by $\mathrm{H}$ and F, respectively. The total measure of population in the union is normalized to unity. The home country, $\mathrm{H}$, is inhabited by a continuum of households on the interval $[0, \gamma]$, and the foreign country, $\mathrm{F}$, is populated by the rest of the households on the interval $[\gamma, 1]$. There is no labor 
mobility across countries. Unlike Benigno (2004), we follow Gail and Monacelli (2008) and Ferrero (2009), and assume that both the domestic and international financial markets are complete. Though there exists a separate fiscal authority for each country, a common central bank conducts the monetary policy for the entire union. The nonenergy consumption goods are produced by monopolistically competitive firms, each using domestic labor and energy to produce a differentiated product. The consumption basket of a home representative household includes not only domestic and imported consumption goods but also energy. Thus, there is a distinction between headline and core inflation.

\subsection{Households}

The representative household $j \in(0,1)$ in country $k \in\{H, F\}$ maximizes the following utility function

$$
\mathbf{E}_{0} \sum_{t=0}^{\infty} \beta^{t} U\left(C_{t}^{j}, L_{t}^{j}\right)=\mathbf{E}_{0} \sum_{t=0}^{\infty} \beta^{t}\left[\frac{\left(C_{t}^{j}\right)^{1-\sigma}}{1-\sigma}-\frac{\left(L_{t}^{j}\right)^{1+\varphi}}{1+\varphi}\right],
$$

where $\beta \in(0,1)$ is the discount factor, $C_{t}^{j}$ is consumption, and $L_{t}^{j}$ is labor supplied by household $j$. When $j \in(0, \gamma)$, it follows that $k=H$, while when $j \in(\gamma, 1)$, it follows that $k=F$. The consumption $C_{t}^{j}$ is a composite of non-energy consumption goods $C_{n t}^{j}$ and energy goods $C_{e t}^{j}$, such that

$$
C_{t}^{j}=\frac{\left(C_{n t}^{j}\right)^{1-\alpha}\left(C_{e t}^{j}\right)^{\alpha}}{(1-\alpha)^{1-\alpha} \alpha^{\alpha}}
$$

Non-energy consumption goods, $C_{n t}^{j}$, are a composite of domestic and imported goods, such that

$$
C_{n t}^{j}=\frac{\left(C_{n t}^{j, H}\right)^{1-\gamma}\left(C_{n t}^{j, \gamma}\right)^{1-\gamma}}{\gamma^{\gamma}(1-\gamma)^{1-\gamma}} .
$$

Accordingly $C_{n t}^{j, H}$ and $C_{n t}^{j, F}$ are CES aggregates across the continuum of differentiated non-energy consumption goods produced in the home and foreign country, respectively. Specifically, 


$$
\begin{aligned}
C_{n t}^{j, H} & \equiv\left[\left(\frac{1}{\gamma}\right)^{\frac{1}{\varepsilon}} \int_{0}^{\gamma} C_{n t}^{j, H}(i)^{\frac{\varepsilon-1}{\varepsilon}} d i\right]^{\frac{\varepsilon}{\varepsilon-1}} \\
C_{n t}^{j, F} & \equiv\left[\left(\frac{1}{1-\gamma}\right)^{\frac{1}{\varepsilon}} \int_{\gamma}^{1} C_{n t}^{j, F}(i)^{\frac{\varepsilon-1}{\varepsilon}} d i\right]^{\frac{\varepsilon}{\varepsilon-1}},
\end{aligned}
$$

where $\varepsilon>1$ is the elasticity of substitution across non-energy consumption goods produced within a country.

Solving the representative household $j$ 's expenditure-minimization problem gives rise to

$$
\begin{gathered}
C_{n t}^{j, H}(i)=(1-\alpha)\left(\frac{P_{n t}^{H}(i)}{P_{n t}^{H}}\right)^{-\varepsilon} S_{n t}^{1-\gamma} \Psi_{e t}^{-\alpha} C_{t}^{j}, i \in(0, \gamma) \\
C_{n t}^{j, F}(i)=(1-\alpha)\left(\frac{P_{n t}^{F}(i)}{P_{n t}^{F}}\right)^{-\varepsilon} S_{n t}^{-\gamma} \Psi_{e t}^{-\alpha} C_{t}^{j}, i \in(\gamma, 1) \\
C_{e t}^{j}=\alpha \frac{P_{t}}{P_{e t}} C_{t}^{j}=\alpha \Psi_{e t}^{1-\alpha} C_{t}^{j},
\end{gathered}
$$

where $P_{t}=P_{e t}^{\alpha} P_{n t}^{1-\alpha}$ is the CPI, $P_{e t}$ is the energy price, $P_{n t}=\left(P_{n t}^{H}\right)^{\gamma}\left(P_{n t}^{F}\right)^{1-\gamma}$ is the price index for non-energy consumption goods, $P_{n t}^{H}=\left[\frac{1}{\gamma} \int_{0}^{\gamma} P_{n t}^{H}(i)^{1-\varepsilon} d i\right]^{\frac{1}{1-\varepsilon}}$ is the price index for home non-energy consumption goods, $P_{n t}^{F}=\left[\frac{1}{1-\gamma} \int_{\gamma}^{1} P_{n t}^{F}(i)^{1-\varepsilon} d i\right]^{\frac{1}{1-\varepsilon}}$ is the price index for foreign non-energy consumption goods, $\Psi_{e t}=\frac{P_{n t}}{P_{e t}}$ is the relative price of non-energy consumption goods in terms of energy good, and $S_{n t}=\frac{P_{n t}^{F}}{P_{n t}^{H}}$ is the terms of trade.

The representative household $j \in(0,1)$ maximizes equation (1) subject to the following budget constraint

$$
P_{t} C_{t}^{j}+\sum_{s_{t+1} \in \Omega_{t+1}} Z\left(s_{t+1} \mid s_{t}\right) D^{j}\left(s_{t+1}\right)=W_{t}^{k} L_{t}^{j}+D^{j}\left(s_{t}\right)-T_{t}^{k}+\Gamma_{t}^{k},
$$

in which $D^{j}\left(s_{t}\right)$ is the nominal payoffs on state-contingent claims for state $s_{t}$, 
purchased by household $j$ at time $t, Z\left(s_{t+1} \mid s_{t}\right)$ is the state $s_{t}$ price of a claim that yields one unit of currency in state $s_{t+1}, W_{t}^{k}$ is the nominal wage, $T_{t}^{k}$ denotes lumpsum taxes, and $\Gamma_{t}^{k}$ denotes aggregate profits accruing from ownership of home firms.

The first-order condition for labor supply is given by

$$
\frac{W_{t}^{k}}{P_{t}}=\left(C_{t}^{j}\right)^{\sigma}\left(L_{t}^{j}\right)^{\varphi} .
$$

Equation (9) implies that the marginal rate of substitution between leisure and consumption is equal to the real wage.

The intertemporal consumption choice is described by

$$
\beta\left(\frac{C_{t+1}^{j}}{C_{t}^{j}}\right)^{-\sigma} \frac{P_{t}}{P_{t+1}}=Q\left(s_{t+1} \mid s_{t}\right),
$$

where $Q\left(s_{t+1} \mid s_{t}\right)=\frac{Z\left(s_{t+1} \mid s_{t}\right)}{\operatorname{Pr}\left(s_{t+1} \mid s_{t}\right)}$ is the normalized price of the state contingent claim. Equation (10) implies that the intertemporal marginal rate of substitution is equal to the price of the state contingent claim. Taking expectations on both sides of equation (10), we obtain the stochastic Euler equation:

$$
\beta R_{t} \mathbf{E}_{t}\left[\left(\frac{C_{t+1}^{j}}{C_{t}^{j}}\right)^{-\sigma} \frac{P_{t}}{P_{t+1}}\right]=1,
$$

where $R_{t}=\left[E_{t} Z\left(s_{t+1} \mid s_{t}\right)\right]^{-1}$ is the gross nominal return on a riskless one-period bond.

\subsection{Firms}

The total measure of firms is unity worldwide, where the firms in the interval $(0, \gamma)$ are located in the home country, while the rest of the firms are located in the foreign country. The representative firm $i \in(0,1)$ produces a differentiated non-energy consumption good with the following technology

$$
Y_{n t}^{k}(i)=A_{t}^{k} L_{t}^{k}(i)^{1-\delta} O_{t}^{k}(i)^{\delta},
$$

in which $A_{t}^{k}$ is a productivity shock common to all firms in each country, while $L_{t}^{k}(i)$ and $O_{t}^{k}(i)$ are labor and energy employed, respectively. When $i \in(0, \gamma)$, it follows that 
$k=H$, while when $i \in(\gamma, 1)$, it follows that $k=F$. The labor markets are segmented, with wage determined competitively in each country. Non-energy consumption goods are traded freely worldwide.

Letting $a_{t}^{k}=\ln A_{t}^{k}$, we assume that the productivity shock evolves according to the AR(1) process

$$
a_{t}^{k}=\rho^{k} a_{t-1}^{k}+\varepsilon_{t}^{k},
$$

where $\rho^{k} \in(0,1), \quad \varepsilon_{t}^{k} \sim N\left(0, \sigma_{k}^{2}\right)$.

Solving firm $i$ 's cost-minimization problem, we can obtain its unit cost function: $M C_{t}^{k}=(1-\delta)^{\delta-1} \delta^{-\delta} \frac{1}{A_{t}^{k}}\left(W_{t}^{k}\right)^{1-\delta} P_{e t}^{\delta}$. The demands for labor and energy are given, respectively, by

$$
L_{t}^{k}(i)=(1-\delta) \frac{M C_{t}^{k}}{W_{t}^{k}} Y_{n t}^{k}(i), O_{t}^{k}(i)=\delta \frac{M C_{t}^{k}}{P_{e t}} Y_{n t}^{k}(i)
$$

Firms set prices in a staggered fashion, as in Calvo (1983). In each period, independently of previous adjustments, the representative firm $i \in(0,1)$ can adjust its price with a probability $1-\theta^{k}$. In the event of a price adjustment in period $t$, it chooses $P_{n t}^{k^{*}}(i)$ to maximize

$$
\mathbf{E}_{t} \sum_{\tau=t}^{\infty}\left(\theta^{k}\right)^{\tau-t}\left\{\Lambda_{t, \tau}\left[P_{n t}^{k *}(i)\left(1+\tau^{k}\right)-M C_{n \tau \mid t}^{k}\right] Y_{n \tau \mid t}^{k}(i)\right\}
$$

subject to the demand schedule given by

$$
\begin{aligned}
& Y_{n \tau \mid t}^{k}(i)=(1-\alpha)\left(\frac{P_{n t}^{k *}(i)}{P_{n \tau}^{k}}\right)^{-\varepsilon} S_{n \tau}^{1-\gamma} \Psi_{e \tau}^{-\alpha} C_{\tau}^{W}, i \in(0, \gamma) \\
& Y_{n \tau \mid t}^{k}(i)=(1-\alpha)\left(\frac{P_{n t}^{k *}(i)}{P_{n \tau}^{k}}\right)^{-\varepsilon} S_{n \tau}^{-\gamma} \Psi_{e \tau}^{-\alpha} C_{\tau}^{W}, i \in(\gamma, 1),
\end{aligned}
$$

in which $\Lambda_{t, \tau}=\beta^{\tau-t}\left(C_{\tau} / C_{t}\right)^{-\sigma}\left(P_{t} / P_{\tau}\right)$ is the stochastic discount factor, $\tau^{k}$ is the common subsidy given to firms in country $k, M C_{n \tau \mid t}^{k}$ and $Y_{n \tau \mid t}^{k}(i)$ represent the unit 
cost and output of firm $i \in(0,1)$ in period $\tau$. That firm last reset its price in period $t$, and $C_{\tau}^{W}=\int_{0}^{1} C_{\tau}^{j} d j$ is aggregate consumption in the union. The optimally adjusted price for firm $i \in(0,1)$ is given by

$$
P_{n t}^{k *}(i)=\frac{\varepsilon}{(\varepsilon-1)\left(1+\tau^{k}\right)} \frac{\mathbf{E}_{t} \sum_{\tau=t}^{\infty}\left(\theta^{k}\right)^{\tau-t} \Lambda_{t, \tau} M C_{n \tau \mid t}^{k} Y_{n \tau \mid t}(i)}{\mathbf{E}_{t} \sum_{\tau=t}^{\infty}\left(\theta^{k}\right)^{\tau-t} \Lambda_{t, \tau} Y_{n \tau \mid t}(i)},
$$

in which $\frac{\varepsilon}{(\varepsilon-1)\left(1+\tau^{k}\right)}$ is markup adjusted by subsidy.

\section{Equilibrium}

Define home and foreign aggregate output as $Y_{n t}^{H}=\left[\left(\frac{1}{\gamma}\right)^{\frac{1}{\varepsilon}} \int_{0}^{\gamma} Y_{n t} \%^{H}(i)^{\frac{\varepsilon-1}{\varepsilon}} d i\right]^{\frac{\varepsilon}{\varepsilon-1}}$ and $Y_{n t}^{F} \equiv\left[\left(\frac{1}{1-\gamma}\right)^{\frac{1}{\varepsilon}} \int_{\gamma}^{1} Y_{n t}^{F}(i)^{\frac{\varepsilon-1}{\varepsilon}} d i\right]^{\frac{\varepsilon}{\varepsilon-1}}$, respectively. By the market-clearing conditions given by equations (16) and (17), we know that $Y_{n t}^{H}=\gamma(1-\alpha) S_{n t}^{1-\gamma} \Psi_{e t}^{-\alpha} C_{t}^{W}$ and $Y_{n t}^{F} \equiv(1-\gamma)(1-\alpha) S_{n t}^{-\gamma} \Psi_{e t}^{1-\alpha} C_{t}^{W}$

Aggregate labor demands in both countries are given, respectively, by

$$
\begin{gathered}
L_{t}^{H}=\int_{0}^{\gamma} L_{t}^{H}(i) d i=\gamma(1-\delta)(1-\alpha) \frac{M C_{t}^{H}}{W_{t}^{H}} S_{n t}^{1-\gamma} \Psi_{e t}^{-\alpha} C_{t}^{W} D_{t}^{H} \\
L_{t}^{F}=\int_{\gamma}^{1} L_{t}^{F}(i) d i=(1-\gamma)(1-\delta)(1-\alpha) \frac{M C_{t}^{H}}{W_{t}^{H}} S_{n t}^{-\gamma} \Psi_{e t}^{-\alpha} C_{t}^{W} D_{t}^{F},
\end{gathered}
$$

in which $D_{t}^{H}=\int_{0}^{\gamma}\left(\frac{P_{n t}^{H}(i)}{P_{n t}^{H}}\right)^{-\varepsilon} d i$ and $D_{t}^{F}=\int_{\gamma}^{1}\left(\frac{P_{n t}^{F}(i)}{P_{n t}^{F}}\right)^{-\varepsilon} d i$ are home and foreign price dispersions. Those dispersions are of second order.

Following Bodenstein et al. (2008, 2013) and Devereux et al. (2010), we assume that, in each period, the world is endowed with an exogenous energy endowment $O_{t}^{s}$. The oil price $P_{e t}$ varies endogenously to clear the world oil market, where 


$$
O_{t}^{s}=C_{e t}^{W}+O_{t}^{H}+O_{t}^{F}
$$

in which $C_{e t}^{W}=\int_{0}^{1} C_{e t}^{j} d j, O_{t}^{H}=\int_{0}^{\gamma} O_{t}^{H}(i) d i$, and $O_{t}^{F}=\int_{\gamma}^{1} O_{t}^{F}(i) d i$. Exogenous energy endowment $O_{t}^{s}$ is governed by the following stochastic process

$$
o_{t}^{s}=\rho_{o} o_{t-1}^{s}+\varepsilon_{t}^{o}
$$

in which $o_{t}^{s}=\ln O_{t}^{s}, \rho_{o} \in(0,1)$, and $\varepsilon_{t}^{o} \sim N\left(0, \sigma_{o}^{2}\right)$.

\subsection{The steady state}

The steady state follows, when $O_{t}^{s}=A_{t}^{H}=A_{t}^{F}=1$. The monopoly power owned by firms implies that a steady-state markup distortion emerges. To eliminate the distortion and restore efficiency, we assume that the fiscal authority in each country subsidizes the production with a subsidy, raised in a lump-sum fashion from the households.

To eliminate the linear terms, when taking a second-order approximation to the joint utility function of the whole union, we need several crucial steady-state ratios. The ratio of home to foreign employment is $\frac{L^{H}}{L^{F}}=\frac{\gamma}{1-\gamma}$. Furthermore, the ratio of energy consumption to total endowment is $\frac{C_{e}^{W}}{O^{s}}=\frac{\alpha}{\alpha+\delta(1-\alpha)}$. Thus, the ratio of energy input in production to total endowment is $\frac{O^{H}+O^{F}}{O^{S}}=\frac{\delta(1-\alpha)}{\alpha+\delta(1-\alpha)}$. Another useful steady-state relationship is $C^{1-\sigma}=(1-\delta)(1-\alpha) N^{1+\varphi}$.

\subsection{The flexible-price equilibrium}

To obtain an efficient flexible-price equilibrium, we assume that the markup distortions can be eliminated by government subsidies. In addition, following Bodenstein et al. (2008), we assume that the coefficient of relative risk aversion is unity, with the utility function of consumption that is logarithmic. In the following, we use a lower-case variable with an upper bar to represent the deviation of the log of the corresponding flexible-price variable from its steady-state value.

Home output can be expressed as

$$
\bar{y}_{n t}^{H}=(1-\gamma) \bar{s}_{n t}+\bar{c}_{n t}=\delta o_{t}^{s}+a_{t}^{H} .
$$


The foreign counterpart of equation (23) is

$$
\bar{y}_{n t}^{F}=-\gamma \bar{s}_{n t}+\bar{c}_{n t}=\delta o_{t}^{s}+a_{t}^{F} .
$$

The terms of trade are the difference between home and foreign productivity shocks, given by

$$
\bar{s}_{n t}=\bar{y}_{n t}^{H}-\bar{y}_{n t}^{F}=a_{t}^{H}-a_{t}^{F} .
$$

Since domestic financial markets are complete, home households consume the same amount of goods. Furthermore, complete international financial markets, together with the assumption that there is no home bias in consumption, imply that the consumption level of the home representative household is identical to that of the foreign counterpart,

$$
\bar{c}_{t}^{j}=\Theta_{o} o_{t}^{s}+\gamma \Theta_{H} a_{t}^{H}+(1-\gamma) \Theta_{H} a_{t}^{F} \text {, for any } j \in[0,1],
$$

where $\Theta_{o}=\alpha+\delta-\delta \alpha, \Theta_{H}=1-\alpha$.

The relative price of non-energy consumption goods in terms of energy goods is

$$
\bar{\psi}_{e t}=(1-\delta) o_{t}^{s}-\gamma a_{t}^{H}-(1-\gamma) a_{t}^{F} .
$$

Intuitively, $\bar{\psi}_{e t}$ increases with the endowment of energy goods and decreases with positive productivity shocks.

\subsection{The sticky-price equilibrium}

In this section, we express the sticky-price equilibrium as a log-linear approximation around the steady state. A lower-case variable refers to the log deviation of the corresponding upper-case variable from its steady state value.

Log-linearization of equation (9) and its foreign counterpart yields

$$
\begin{gathered}
\eta_{H t}=\sigma c_{t}+\varphi l_{t}^{H}+(1-\gamma) s_{n t}-\alpha \psi_{e t} \\
\eta_{F t}=\sigma c_{t}+\varphi l_{t}^{F}-\gamma s_{n t}-\alpha \psi_{e t},
\end{gathered}
$$

in which $\eta_{H t}=\ln \frac{W_{t}^{H}}{P_{n t}^{H}}-\ln \frac{W^{H}}{P_{n}^{H}}$ and $\eta_{F t}=\ln \frac{W_{t}^{F}}{P_{n t}^{F}}-\ln \frac{W^{F}}{P_{n}^{F}}$ are the home and foreign domestic consumption-goods wages, respectively. Other things being equal, when the relative price of non-energy consumption goods in terms of energy goods rises, both home and foreign domestic consumption goods wages decrease. As a comparison, when 
the terms of trade in the home country deteriorate, home consumption goods are cheaper than foreign consumption goods. Thus, home domestic consumption goods wage goes up, while foreign domestic consumption goods wage is depressed.

From the non-energy consumption goods production function in both countries, we have

$$
\begin{gathered}
y_{n t}^{H}=a_{t}^{H}+l_{t}^{H}+\delta\left[\eta_{H t}-(1-\gamma) s_{n t}+\psi_{e t}\right] \\
y_{n t}^{F}=a_{t}^{F}+l_{t}^{F}+\delta\left[\eta_{F t}+\gamma s_{n t}+\psi_{e t}\right] .
\end{gathered}
$$

In equations (30) and (31), we have used firms' cost-minimization conditions $o_{t}^{H}-l_{t}^{H}=\eta_{H t}-(1-\gamma) s_{n t}+\psi_{e t}$, and $o_{t}^{F}-l_{t}^{F}=\eta_{F t}+\gamma s_{n t}+\psi_{e t}$, respectively.

Log-linearizing the market-clearing conditions of non-energy consumption goods in both countries, we obtain

$$
\begin{gathered}
y_{n t}^{H}=(1-\gamma) s_{n t}+c_{n t}^{W} \\
y_{n t}^{F}=-\gamma s_{n t}+c_{n t}^{W},
\end{gathered}
$$

in which $c_{n t}^{W}=\int_{0}^{1} C_{n t}^{j} d j$ is non-energy consumption in the union as a whole. Loglinearization of the market-clearing condition of energy goods yields

$$
\begin{aligned}
& o_{t}^{s}=\frac{\alpha}{\alpha+\delta(1-\alpha)}\left[\delta \psi_{e t}+\gamma a_{t}^{H}+(1-\gamma) a_{t}^{F}-(1-\delta)\left(\gamma \eta_{H t}+(1-\gamma) \eta_{F t}\right)\right] \\
& +\gamma \eta_{H t}+(1-\gamma) \eta_{F t}+\gamma l_{t}^{H}+(1-\gamma) l_{t}^{F}+\psi_{e t},
\end{aligned}
$$

in which $\left.(1-\delta)\left(\gamma \eta_{H t}+(1-\gamma) \eta_{F t}\right)-\delta \psi_{e t}-\gamma a_{t}^{H}-(1-\gamma) a_{t}^{F}\right]$ is the demand of firms for energy goods, relative to that of households in both countries.

The relationship between non-energy consumption and the aggregate consumption in the union as a whole can be described as

$$
c_{n t}^{W}=-\alpha \psi_{e t}+c_{t}^{W} .
$$

Similarly, the relationship between consumption of energy goods and non-energy consumption in the union is

$$
c_{e t}^{W}=\psi_{e t}+c_{n t}^{W} .
$$

From equations (28) to (36), and using the fact that the aggregate non-energy 
consumption is equal to the aggregate non-energy output, so that $c_{n t}^{W}=y_{n t}^{W}=\gamma y_{n t}^{H}+(1-\gamma) y_{n t}^{F} \quad, \quad$ we can express the variables $\eta_{H t}, \eta_{F t}, \psi_{e t}, c_{t}, l_{t}^{H}, l_{t}^{F}, c_{e t}^{W}, y_{n t}^{H}, y_{n t}^{F}, c_{n t}, s_{n t}$ in terms of non-energy output $y_{n t}^{W}$ in the union, the terms of trade $s_{n t}$, and other exogenous variables.

After some algebra, we can express home and foreign employment respectively as

$$
\begin{aligned}
& l_{t}^{H}=\frac{1-\delta \Omega_{c}}{1+\delta \Omega_{B}} y_{n t}^{W}+\frac{1-\gamma}{1+\delta \varphi} S_{n t}-\frac{\delta \Omega_{o}}{1+\delta \Omega_{B}} o_{t}^{s} \\
& -\left(\gamma \frac{1+\delta \Omega_{H}}{1+\delta \Omega_{B}}+\frac{1-\gamma}{1+\delta \varphi}\right) a_{t}^{H}-(1-\gamma)\left(\frac{1+\delta \Omega_{H}}{1+\delta \Omega_{B}}-\frac{1}{1+\delta \varphi}\right) a_{t}^{F} \\
& l_{t}^{F}=\frac{1-\delta \Omega_{c}}{1+\delta \Omega_{B}} y_{n t}^{W}-\frac{\gamma}{1+\delta \varphi} S_{n t}-\frac{\delta \Omega_{o}}{1+\delta \Omega_{B}} o_{t}^{s} \\
& -\gamma\left(\frac{1+\delta \Omega_{H}}{1+\delta \Omega_{B}}-\frac{1}{1+\delta \varphi}\right) a_{t}^{H}-\left((1-\gamma) \frac{1+\delta \Omega_{H}}{1+\delta \Omega_{B}}+\frac{\gamma}{1+\delta \varphi}\right) a_{t}^{F},
\end{aligned}
$$

where $\Omega_{c}=\frac{\alpha}{\alpha+\delta}, \Omega_{B}=\left(\frac{\alpha}{\alpha+\delta} \varphi-\Omega_{o}\right), \Omega_{o}=\frac{\alpha+\delta(1-\alpha)}{\delta+\alpha}$, and $\Omega_{H}=-\frac{\alpha}{\alpha+\delta}$.

Intuitively, when the output in the union as a whole rises, the demands for home and foreign labor increase at the same time. However, the expenditure-switching mechanism of the terms of trade implies that, when the terms of trade in the home country deteriorate, the demand for home labor increases, while the demand for foreign labor decreases. The substitution between labor and energy means that, when energy supply goes up, the labor input goes down in both countries. In addition, a positive productivity shock in either country decreases the demand for labor in both countries. ${ }^{3}$

We can also express the home and foreign domestic consumption-goods wages respectively as

$$
\begin{aligned}
& \eta_{H t}=\left(1+\varphi \frac{1-\delta \Omega_{c}}{1+\delta \Omega_{B}}\right) y_{n t}^{W}+(1-\gamma)\left(1+\frac{\varphi}{1+\delta \varphi}\right) s_{n t}-\varphi \frac{\delta \Omega_{o}}{1+\delta \Omega_{B}} o_{t}^{s} \\
& -\left(\gamma \varphi \frac{1+\delta \Omega_{H}}{1+\delta \Omega_{B}}+\frac{(1-\gamma) \varphi}{1+\delta \varphi}\right) a_{t}^{H}-(1-\gamma)\left(\varphi \frac{1+\delta \Omega_{H}}{1+\delta \Omega_{B}}-\frac{\varphi}{1+\delta \varphi}\right) a_{t}^{F}
\end{aligned}
$$

\footnotetext{
3 The analysis follows from the fact that $\frac{1-\delta \Omega_{c}}{1+\delta \Omega_{B}}>0, \frac{\delta \Omega_{o}}{1+\delta \Omega_{B}}>0, \gamma \frac{1+\delta \Omega_{H}}{1+\delta \Omega_{B}}+\frac{1-\gamma}{1+\delta \varphi}>0$, and $\frac{1+\delta \Omega_{H}}{1+\delta \Omega_{B}}-\frac{1}{1+\delta \varphi}>0$.
} 


$$
\begin{aligned}
& \eta_{F t}=\left(1+\varphi \frac{1-\delta \Omega_{c}}{1+\delta \Omega_{B}}\right) y_{n t}^{W}-\gamma\left(1+\frac{\varphi}{1+\delta \varphi}\right) s_{n t}-\varphi \frac{\delta \Omega_{o}}{1+\delta \Omega_{B}} o_{t}^{s} \\
& -\gamma\left(\varphi \frac{1+\delta \Omega_{H}}{1+\delta \Omega_{B}}-\frac{\varphi}{1+\delta \varphi}\right) a_{t}^{H}-\left((1-\gamma) \varphi \frac{1+\delta \Omega_{H}}{1+\delta \Omega_{B}}+\frac{\gamma \varphi}{1+\delta \varphi}\right) a_{t}^{F} .
\end{aligned}
$$

The rise in output in the union as a whole increases the demands for labor and pushes up the wages, but lowers the prices of non-energy consumption goods in both countries. As a result, the relative prices of non-energy consumption goods in terms of energy goods rise. As previously discussed, the deterioration of the terms of trade implies home consumption goods are cheaper than foreign consumption goods. As a result, home domestic consumption goods wage rises, while foreign domestic consumption goods wage falls. When energy endowment goes up, the households tend to substitute energy for non-energy consumption goods, while firms substitute energy for labor input. Both wages and the prices of non-energy consumption goods decline in both countries. However, the decrease in the prices of non-energy consumption goods lowers the demands for non-energy consumption goods and depresses wages further. Consequently, the relative prices of non-energy consumption goods in terms of energy goods fall in both countries. The effects of positive productivity shocks in both countries can be analyzed similarly.

The relative price of non-energy consumption goods in terms of energy good depends on the aggregate non-energy output, exogenous energy endowment, and productivity shocks, given by

$$
\psi_{e t}=-\Phi_{c} y_{n t}^{W}+\Phi_{o} o_{t}^{s}+\gamma \Phi_{H} a_{t}^{H}+(1-\gamma) \Phi_{H} a_{t}^{F}
$$

where

$$
\begin{gathered}
\Phi_{c}=\frac{a(\delta-1)^{2}+\delta \varphi+\delta(2-\delta)}{a(1+\delta \varphi)+(1-\delta) \delta(1-a)}>0, \\
\Phi_{o}=\frac{(\alpha+\delta(1-\alpha))\left(1+\delta \Omega_{B}+\delta \Omega_{o}\right)+\delta^{2} \varphi \Omega_{o}}{(\alpha+\delta)\left(1+\delta \Omega_{B}\right)}>0
\end{gathered}
$$

and

$$
\Phi_{H}=\frac{\left(1+\delta \Omega_{H}\right)(\alpha+\delta(1-\alpha)+\delta \varphi)}{\left(1+\delta \Omega_{B}\right)(\alpha+\delta)}-\frac{\alpha}{\delta+\alpha}>0
$$


The increase in the aggregate non-energy output in the union as a whole lowers the price of non-energy consumption goods. Thus the relative price of non-energy consumption goods in terms of energy goods falls. As a comparison, the increase in the energy endowment lowers the price of energy good, thereby pushing up the relative price of non-energy consumption goods in terms of energy goods. The effect of positive productivity shocks on the relative price of non-energy consumption goods in terms of energy goods is more complicated. A positive productivity shock in either country increases the aggregate non-energy output in the union as a whole, thereby decreasing the price of non-energy consumption goods. However, after a positive productivity shock occurs in either country, firms need to input less energy to produce a given amount of output. Consequently, the price of energy goods is depressed substantially. The latter effect dominates the former. The relative price of non-energy consumption goods in terms of energy goods rises.

Expressing the marginal cost in either country in terms of domestic price of nonenergy consumption goods, we obtain the real marginal costs, given by

$$
\begin{gathered}
\phi_{n t}^{H}=(1-\delta) \eta_{H t}-\delta \psi_{e t}+\delta(1-\gamma) s_{n t}-a_{t}^{H} \\
\phi_{n t}^{F}=(1-\delta) \eta_{F t}-\delta \psi_{e t}-\delta \gamma s_{n t}-a_{t}^{F} .
\end{gathered}
$$

In the following, a variable with tilde denotes the deviation of the log of the variable from the corresponding value in flexible-price equilibrium. That deviation is referred to as the gap. Using the expressions for $\eta_{H t}, \eta_{F t}$, and $\psi_{e t}$, we obtain the real marginal cost gaps, given by

$$
\begin{gathered}
\tilde{\phi}_{n t}^{H}=\left((1-\delta) A_{c}+\delta \Phi_{c}\right) \tilde{y}_{n t}^{W}+(1-\gamma)\left((1-\delta)\left(1+\frac{\varphi}{1+\delta \varphi}\right)+\delta\right) \tilde{s}_{n t} \\
\tilde{\phi}_{n t}^{F}=\left((1-\delta) A_{c}+\delta \Phi_{c}\right) \tilde{y}_{n t}^{W}-\gamma\left((1-\delta)\left(1+\frac{\varphi}{1+\delta \varphi}\right)+\delta\right) \tilde{s}_{n t},
\end{gathered}
$$

in which $(1-\delta) A_{c}+\delta \Phi_{c}=\frac{(\varphi+1)(\alpha(1-\delta)+\delta)}{\alpha\left(\delta^{2}+\delta \varphi+(1-\delta)\right)+(1-\delta) \delta}>0$. As usual, the real marginal cost gap moves in the same direction as the output gap. As a comparison, a positive terms of trade gap causes a positive real marginal cost gap in the home country, 
but a negative real marginal cost gap in the foreign country.

Log-linearizing the Euler equations around the steady state, we derive, for the union as a whole, a dynamic IS equation, given by

$$
\tilde{y}_{n t}^{W}=\mathbf{E}_{t} \tilde{y}_{n t+1}^{W}-\frac{1}{1-\alpha \Phi_{c}}\left(i_{t}-\mathbf{E}_{t} \pi_{t+1}-\bar{r}_{t}\right),
$$

in which $i_{t}=\ln R_{t}$ is the nominal interest rate of the union, and $\bar{r}_{t}=\mathbf{E}_{t} \Delta \bar{c}_{t+1}^{W}$ is the real interest rate in the flexible-price equilibrium.

The CPI inflation and the non-energy consumption-goods inflation rates in both countries are related according to the following expression

$$
\pi_{t}=\gamma \pi_{n t}^{H}+(1-\gamma) \pi_{n t}^{F}+\alpha \Phi_{c}\left(\tilde{y}_{n t}^{W}-\tilde{y}_{n t-1}^{W}\right)+\alpha \Phi_{c}\left(\bar{y}_{n t}^{W}-\bar{y}_{n t-1}^{W}\right) .
$$

Under the Calvo price setting mechanism, the price of non-energy consumption goods in the home country evolves as

$$
P_{n t}^{H}=\left[\theta^{H}\left(P_{n t-1}^{H}\right)^{1-\varepsilon}+\left(1-\theta^{H}\right)\left(P_{n t}^{H^{*}}\right)^{1-\varepsilon}\right]^{\frac{1}{1-\varepsilon}} .
$$

Following the familiar procedures in the literatures, we derive a New Keynesian Phillips curve to describe the motion of the home non-energy consumption-goods inflation,

$$
\pi_{n t}^{H}=\beta \mathbf{E}_{t} \pi_{n t+1}^{H}+\lambda^{H}\left\{\left((1-\delta) A_{c}+\delta \Phi_{c}\right) \tilde{y}_{n t}^{W}+(1-\gamma)\left((1-\delta)\left(1+\frac{\varphi}{1+\delta \varphi}\right)+\delta\right) \tilde{s}_{n t}\right\},
$$

in which $\lambda^{H}=\frac{\left(1-\beta \theta^{H}\right)\left(1-\theta^{H}\right)}{\theta^{H}}$.

The foreign counterpart of equation (48) is

$$
\pi_{n t}^{F}=\beta \mathbf{E}_{t} \pi_{n t+1}^{F}+\lambda^{F}\left\{\left((1-\delta) A_{c}+\delta \Phi_{c}\right) \tilde{y}_{n t}^{W}-\gamma\left((1-\delta)\left(1+\frac{\varphi}{1+\delta \varphi}\right)+\delta\right) \tilde{s}_{n t}\right\},
$$

in which $\lambda^{F}=\frac{\left(1-\beta \theta^{F}\right)\left(1-\theta^{F}\right)}{\theta^{F}}$.

The terms of trade gap is associated with the non-energy consumption-goods inflation rate in both countries in accordance with this identity:

$$
\tilde{s}_{n t}=\tilde{s}_{n t-1}+\pi_{n t}^{F}-\pi_{n t}^{H}-\left(\Delta a_{t}^{H}-\Delta a_{t}^{F}\right),
$$


in which $\Delta a_{t}^{H}=a_{t}^{H}-a_{t-1}^{H}$ and $\Delta a_{t}^{F}=a_{t}^{F}-a_{t-1}^{F}$. Equations (46)-(50) constitute the equilibrium system of our model. To close the model, we need to supplement equations (46)-(50) with one equation describing how the nominal interest rate, $i_{t}$, evolves over time, to describe how monetary policy is conducted. We will introduce various monetary policy rules in the subsequent section.

\section{Monetary policy analysis}

When exporters set prices in their own currency (producer-currency pricing or PCP) with no cost-push shock, Clarida et al. (2002) show that the "divine coincidence" (Blanchard and Gali, 2007) holds. The "divine coincidence" refers to a situation in which the optimal monetary policy can stabilize the inflation and the output gap simultaneously, as also holds in a standard closed-economy New Keynesian model (Gali, 2008). However, when there are multiple nominal rigidities (Erceg et al., 2000) or multiple sectors (Huang and Liu, 2005; Gong et al. 2016), the "divine coincidence" breaks down. In a two-country currency-union model with staggered price setting, Benigno (2004) shows that the efficient allocation is not feasible, even if there is no cost-push shock. The conclusion still holds after we introduce energy good in consumption and production.

Proposition 1. In a two-country, currency-union, New Keynesian model with energy goods in consumption and production, it is impossible to implement the flexible-price equilibrium allocation.

Proof. We prove the proposition by contradiction. Suppose there were a monetary policy with which the flexible-price equilibrium allocation can be implemented. Then $\tilde{y}_{n t}^{W}=\tilde{s}_{n t}=0$ for all $t$, so that $\pi_{n t}^{H}=\pi_{n t}^{F}=0$ for at $t$. However, from equation (50), we know that $\pi_{n t}^{H}=\pi_{n t}^{F}=\Delta a_{t}^{H}-\Delta a_{t}^{F}$, which contradicts $\pi_{n t}^{H}=\pi_{n t}^{F}=0$ for all $t$.

In Clarida et al. (2002), after productivity shocks occur, the monetary policymaker keeps the inflation rate at zero to eliminate distortions caused by price stickiness in either country. Meanwhile, the nominal exchange rate fluctuates to adjust the relative price of home consumption goods in terms of their foreign counterparts. Consequently, 
the output gap is also closed in either country, and the "divine coincidence" is realized.

By comparison, in our model, when the monetary policymaker chooses zero inflation rate in the union to eliminate price stickiness distortions, it is impossible to close output gaps in both countries. The reason is that the nominal exchange rate is absent to adjust the relative price of home consumption goods in terms of their foreign counterparts. Therefore, the "divine coincidence" breaks down.

\subsection{Optimal monetary policy}

Now we analyze optimal monetary policy, particularly focusing on the role played by energy goods, included in both consumption and production. The presence of energy goods in consumption makes it possible to distinguish the headline inflation rate from the core inflation rate. The inclusion of energy goods in the production function changes the real marginal costs, which can be monetary policy targets. In the following, we follow Woodford (2003) and derive a quadratic welfare-theoretic loss function facing the monetary policymaker by taking a second-order approximation to the joint utility function of home and foreign households around the efficient steady state.

The monetary policymaker wishes to minimize the following welfare-theoretic loss function $^{4}$

$$
\mathbf{W}=\frac{1}{2} \mathbf{E}_{0} \sum_{t=0}^{\infty} \beta^{t} \mathbf{X}_{t}+(t . i . p)+O\left(\|a\|^{3}\right),
$$

in which

$$
\begin{aligned}
& \mathbf{X}_{t}=\frac{1-\alpha}{2}\left\{(1+\varphi)(1-\delta)\left(B_{c}^{2}\left(\tilde{y}_{n t}^{W}\right)^{2}+\frac{\gamma(1-\gamma)}{1+\delta \varphi}\left(\tilde{s}_{n t}\right)^{2}\right)\right. \\
& +\frac{\varepsilon \gamma \theta^{H}}{\left(1-\beta \theta^{H}\right)\left(1-\theta^{H}\right)}\left(\pi_{n t}^{H}\right)^{2}+\frac{\varepsilon(1-\gamma) \theta^{F}}{\left(1-\beta \theta^{F}\right)\left(1-\theta^{F}\right)}\left(\pi_{n t}^{F}\right)^{2} \\
& \left.+\frac{\alpha \delta \gamma}{\alpha+\delta(1-\alpha)}\left[1-\gamma \frac{O_{H}+O_{F}}{O s}\right]\left(\tilde{\phi}_{n t}^{H}\right)^{2}+\frac{\alpha \delta(1-\gamma)}{\alpha+\delta(1-\alpha)}\left[1-(1-\gamma) \frac{O_{H}+O_{F}}{O s}\right]\left(\tilde{\phi}_{n t}^{F}\right)^{2}\right\}
\end{aligned}
$$

where $B_{c}=\frac{a+\delta(1-a)}{a+a \delta \phi+\delta(1-a)(1-\delta)}>0$. In equation (41), (t.i.p) stands for terms independent of policy, and $O\left(\|a\|^{3}\right)$ denotes all relevant terms which are of third or

\footnotetext{
4 The detailed derivation is in the appendix.
} 
higher order.

The expected period welfare loss function can be written as

$$
\begin{aligned}
& \mathbf{L}=\frac{1-\alpha}{2}\left\{(1+\varphi)(1-\delta)\left(B_{c}^{2} \operatorname{var}\left(\tilde{y}_{n t}^{W}\right)+\frac{\gamma(1-\gamma)}{1+\delta \varphi} \operatorname{var}\left(\tilde{s}_{n t}\right)\right)\right. \\
& +\frac{\varepsilon \gamma \theta^{H}}{\left(1-\beta \theta^{H}\right)\left(1-\theta^{H}\right)} \operatorname{var}\left(\pi_{n t}^{H}\right)+\frac{\varepsilon(1-\gamma) \theta^{F}}{\left(1-\beta \theta^{F}\right)\left(1-\theta^{F}\right)} \operatorname{var}\left(\pi_{n t}^{F}\right) \\
& \left.+\frac{\alpha \delta \gamma}{\alpha+\delta(1-\alpha)}\left[1-\gamma \frac{O_{H}+O_{F}}{O s}\right] \operatorname{var}\left(\tilde{\phi}_{n t}^{H}\right)+\frac{\alpha \delta(1-\gamma)}{\alpha+\delta(1-\alpha)}\left[1-(1-\gamma) \frac{O_{H}+O_{F}}{O s}\right] \operatorname{var}\left(\tilde{\phi}_{n t}^{F}\right)\right\} .
\end{aligned}
$$

Due to the presence of price stickiness, the inflation rates of non-energy consumption goods in both countries together with the output gap in the whole union appear in the loss function. These terms are standard in the New Keynesian monetary model. In addition, as discussed previously, in a currency union the nominal exchange rate cannot fluctuate to adjust the relative price of home consumption goods in terms of their foreign counterparts. Thus, the price stickiness also causes a cross-country distortion. Hence, as in Benigno (2004), the terms of trade gap is also present in the loss function. The remaining terms appearing in the loss function are specific to our model.

In a closed-economy New Keynesian monetary model with the energy goods present in consumption and production, Bodenstein et al. (2008) show that the real marginal cost gap reflects costs arising from the inefficient allocation of energy goods between households and firms. Thus, the monetary policymaker should stabilize the real marginal cost gap. Intuitively, in a closed-economy model, when a positive productivity shock occurs, other things being unchanged, firms tend to use less energy goods. Meanwhile, when prices are flexible, the prices of non-energy consumption goods fall and households purchase more non-energy consumption goods. As a result, firms input more energy good to produce more output. However, when prices are sticky, the latter channel, leading to more input of energy goods, is closed. Hence, compared with the allocation in flexible-price equilibrium, the use of energy goods between households and firms is inefficient, and the monetary policymaker should stabilize the 
real marginal cost gap.

In our model, price stickiness also prevents households in the other country from consuming more non-energy consumption goods produced in the country hit by a positive productivity shock. Consequently, firms in the other country use inefficiently more energy good than otherwise. Therefore, the price stickiness not only results in the inefficient allocation of energy goods between households and firms, but also between firms in different countries.

The monetary policymaker chooses $\tilde{y}_{n t}^{W}, s_{n t}, \pi_{n t}^{H}, \pi_{n t}^{F}, \tilde{\phi}_{n t}^{H}, \tilde{\phi}_{n t}^{F}$ to minimize equation (51) subject to constraints (44)-(50). The optimality conditions of this problem, together with constraints (44)-(50), constitute a dynamical system to describe the optimal monetary policy. The optimal monetary policy is obtained under the assumption that the monetary policymaker has the ability to commit to the policy plan.

According to the expected period welfare loss function (53), we can compute the welfare loss under the optimal monetary policy, which is then used as a benchmark to evaluate various monetary policy rules.

\subsection{Simple monetary policy rules}

When conducting monetary policy, what is the appropriate target for the monetary policymaker in a currency union: the core inflation rate or the headline inflation rate? In practice, the European Central Bank targets a weighted average of the Harmonized Index of Consumer Prices of the countries in the union to implement monetary policy. Carefully inspecting the statistics, we find that food and energy, whose prices are nearly flexible, are included in the Harmonized Index of Consumer Prices. Hence, the European Central Bank focuses on the headline inflation rate, when implementing monetary policy. In an influential paper, Benigno (2004) shows that, when the degree of price stickiness is identical in the union, the optimal monetary policy involves targeting a weighted average of the inflation rates in the union, with the weights being equal to the size of the economy in each country. However, Benigno (2004) does not take such goods as food and energy, having flexible prices, into account. Thus, there is no distinction between core inflation rate and headline inflation rate. To fill the gap, we 
introduce energy goods into consumption and production to analyze monetary policy decisions facing the policymaker in a currency union. An advantage is that there now is a distinction between headline and core inflation.

In the following, we assess two different Taylor-type monetary policy rules to answer the question: what is the appropriate target for the monetary policymaker in a currency union, the core inflation rate or the headline inflation rate? One Taylor-type monetary policy rule uses the nominal interest rate to target the headline inflation rate, and the other to target the core inflation rate. The criterion is welfare loss under the optimal monetary policy. The Taylor-type monetary policy rule whose welfare loss is closest to the criterion performs better than the other.

The first rule, the headline inflation Taylor rule (HIT), is specified as

$$
i_{t}=\rho+\phi_{\pi} \pi_{t}+\phi_{y} \tilde{y}_{n t},
$$

where $\rho=-\ln \beta$ is the nominal interest rate in the steady state and $\pi_{t}$ is the headline inflation rate.

The other rule, the core inflation Taylor rule (CIT), is described as

$$
i_{t}=\rho+\phi_{\pi}\left(\gamma \pi_{n t}^{H}+(1-\gamma) \pi_{n t}^{F}\right)+\phi_{y} \tilde{y}_{n t} .
$$

For convenience, we consider the Taylor rule in which the nominal interest rate does not respond to the output gap. But our conclusions still hold, when the nominal interest rate responds to the output gap.

\subsubsection{Calibration}

We calibrate the model at a quarterly frequency. Consistent with the annualized real interest rate of $4 \%$ in the steady state, we set the subjective discount factor $\beta$ to be 0.99 . The intertemporal elasticity of substitution (IES) will be represented by $\sigma$. There is no consensus in the macroeconomics literature on the appropriate value for the IES. Hall (1988) estimates the IES to be close to zero, while Bansal and Yaron (2004) and Gruber (2006) argue for a value greater than 1 . Following most of the literature ${ }^{5}$, we set $\sigma$ to be unity, with utility function of consumption being logarithmic. Similarly, there is a

\footnotetext{
5 See, among many others, Gali and Monacelli (2005, 2016), Bodenstein et al. (2008), and Nakamura and Steinsson (2014).
} 
wide discrepancy between the micro and macro literatures on the estimate of the Frisch elasticity of labor supply, $\phi^{-1}$. We follow Farhi et al. (2014) by setting $\phi$ to be 2 . The elasticity of substitution between differentiated varieties of non-energy consumption goods, $\varepsilon$, is set to be 6 , which implies that the markup is $20 \%$ in the steady state. Following Bodenstein et al. (2008), we set the expenditure shares of energy goods in consumption and production to be $6 \%$ and $2 \%$, respectively. Equivalently, $\alpha=6 \%$ and $\delta=2 \%$. According to Benigno (2004), the expenditure share, $\gamma$, of the households in both countries on non-energy consumption goods produced in the home country is set to be 0.5. The nominal stickiness is assumed to have a duration of four quarters, so that $\theta^{H}=\theta^{F}=0.75$.

At time zero, the union economy is in its non-stochastic steady state. At time 1.0, the economic union is hit by unexpected productivity shocks and an energy endowment shock, uncorrelated with each other. Following Bodenstein et al. (2008), we set $\rho^{H}=\rho^{F}=\rho_{o}=0.8$, to capture the persistence of the shocks, and $\sigma_{H}=\sigma_{F}=\sigma_{o}=0.02$, to describe the volatility of the shocks. Following Taylor's (1993) initial calibration, we set $\phi_{\pi}=1.5$ and $\phi_{y}=0.125$. The parameter values used in the simulation are listed in Table 1.

\subsubsection{Welfare results}

Generally speaking, the conduct of monetary policy depends on the driving force of the economy. In our model, there are two types of shocks, productivity shocks and the energy endowment shock. We first consider the case in which both countries are hit by positive productivity shocks and then a negative energy endowment shock. We compare the welfare loss function incurred by following the HIT with that incurred by following the CIT. The absolute value of the difference between two welfare loss functions represents the welfare gain obtained by following the rule whose welfare loss is closest to that when the optimal monetary policy is implemented.

Table 1: Parameter values in the benchmark case 


\begin{tabular}{lll}
\hline The subjective discount factor & $\beta$ & 0.99 \\
The intertemporal elasticity of substitution & $\sigma$ & 1 \\
The Frisch elasticity of labor supply & $\phi^{-1}$ & $1 / 2$ \\
The elasticity of substitution between non-energy consumption goods & $\varepsilon$ & 6 \\
The expenditure share of energy good in consumption & $\alpha$ & $6 \%$ \\
The expenditure share of energy good in production & $\delta$ & $2 \%$ \\
Country's economic size & $\gamma$ & 0.5 \\
Nominal contract duration i n the home country & $\theta^{\mathrm{H}}$ & 0.75 \\
Nominal contract duration in the foreign country & $\theta^{\mathrm{F}}$ & 0.75 \\
\hline
\end{tabular}

\subsubsection{The source of shocks matters}

Figure 1 reports the welfare gains for various combinations of price stickiness in both countries. When productivity shocks occur in the whole union, the welfare comparison results reveal that the HIT policy performs better than CIT. However, as a comparison, when a negative energy endowment shock occurs, the CIT policy is a better choice.
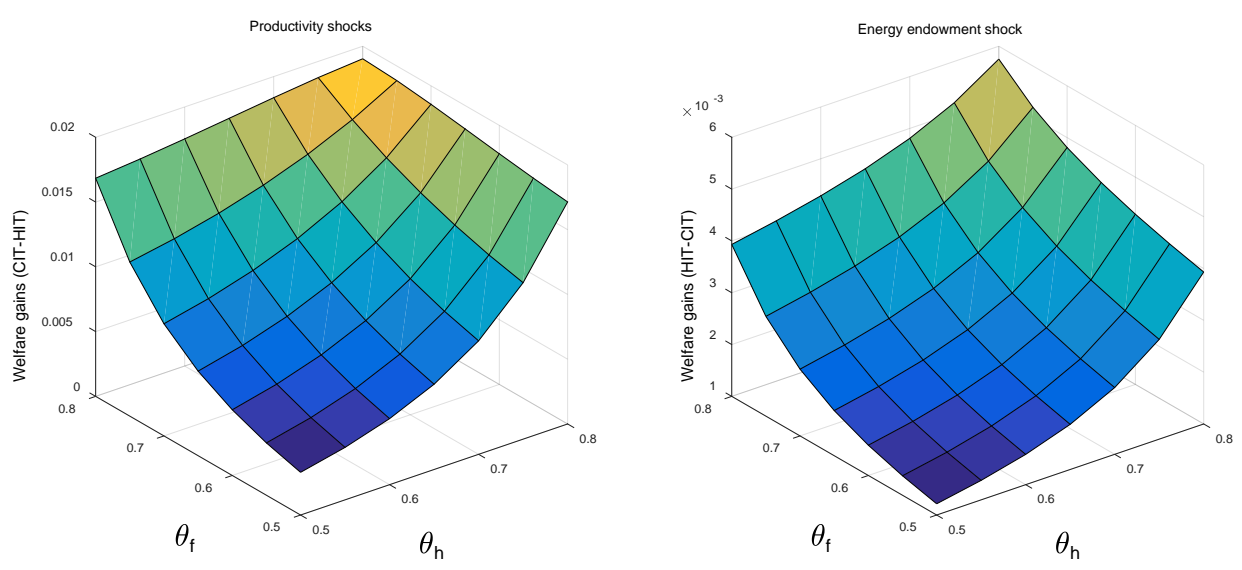

Figure 1. Welfare gains

Observe that the only difference between HIT and CIT is that, when the monetary policymaker follows HIT, the nominal interest rate responds not only to the core inflation rate but also to the inflation rate of the energy good. When the home country is buffeted by a positive productivity shock, the marginal cost of the home non-energy consumption-goods firms falls. In spite of the existence of the nominal rigidity, the 
prices of non-energy consumption-goods adjust downwards gradually. Whether the monetary policymaker targets the headline inflation or the core inflation, the nominal interest rate falls. As a result, the households in the whole union increase expenditure on both energy good and non-energy consumption goods. Both home and foreign nonenergy consumption-goods firms produce more outputs to meet the demands. Thus, except for home non-energy consumption-goods firms, which decrease the energygood input because of technological advance, all other parties increase the demands for the energy good. On the whole, the expansionary demands in the energy-good market push the energy-good price up. Therefore, the decrease in core inflation is greater than the decrease in headline inflation. Upon impact, the CIT policy results in the level of the nominal interest rate being lower than that for the HIT policy.
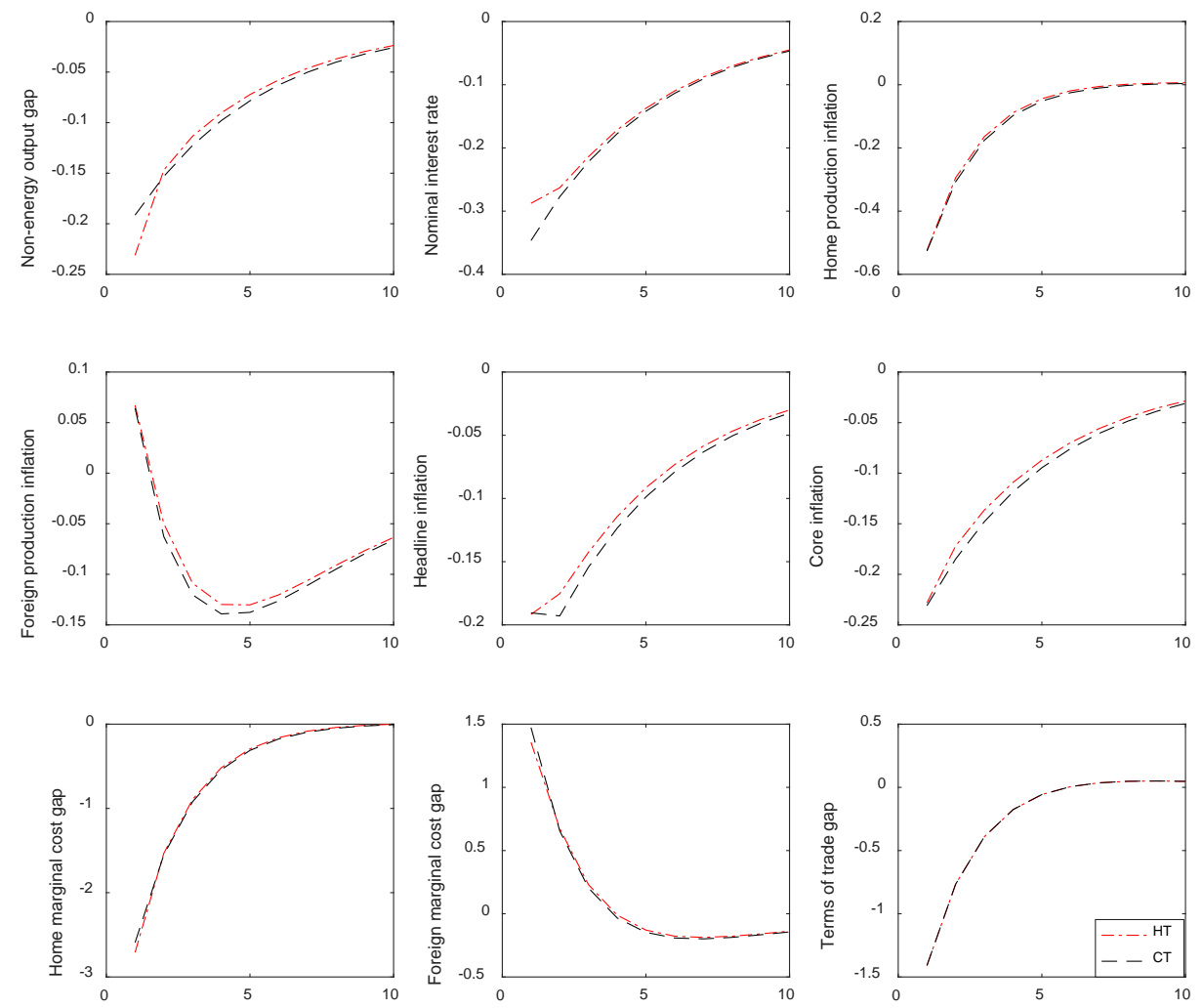

Figure 2: Impulse responses to a home positive productivity shock

The lower nominal interest rate from CIT policy causes more welfare loss than from HIT. We explain the mechanism by analyzing the impulse responses, given by Figure 2. As mentioned above, monetary policy is more expansionary under CIT than under HIT. Consequently, under CIT, higher labor demand causes higher wage in the foreign 
country. In addition, the energy-good price is higher. In the foreign country, marginal cost is higher under CIT than under HIT. In the home country, technological advance reduces the demands of non-energy consumption-goods firms for labor and energy good. Under CIT, the reductions in the demands for the two inputs are smaller than under HIT, because of the more expansionary monetary policy. Thus, home wage declines, with the degree of reduction being smaller under CIT than under HIT.

The response of marginal cost follows the same pattern as the wage in the home country. The impulse responses of the marginal costs confirm our analysis. In the foreign country, the marginal cost gap is positive with the gap being wider under CIT than under HIT. By comparison, in the home country, the marginal cost gap is negative with the gap being narrower under CIT than under HIT. In a model without price rigidity, the more expansionary monetary policy under CIT implies that the foreign non-energy consumption-goods price level rises, with the degree of that rise being higher under CIT than under HIT. By comparison, the home non-energy consumption-goods price level falls, because of the falling marginal cost, with the degree of the decrease being smaller under CIT than under HIT.

However, because of the price rigidity, the adjustment of the non-energy consumption-goods price levels are sluggish. Upon impact, the differences in the impulse responses of home and foreign non-energy consumption-goods inflation rates are very slight under CIT and HIT. The same is also true for the core and headline inflation rates. The slight differences in the home and foreign non-energy consumptiongoods inflation rates result in the nearly identical terms of trade gap under CIT and HIT. In spite of this, both home and foreign non-energy consumption-goods firms produce more outputs. Accordingly, the negative output gap is narrower under CIT than under HIT.

When the initial lower interest rate returns to the steady state more rapidly, the more expansionary monetary policy under CIT turns to be more contractionary than HIT. Thus the rising energy-good price begins to fall more rapidly under CIT than under HIT. The more contractionary monetary policy implies that the foreign non-energy consumption-goods price increases less, but the home non-energy consumption-goods 
price decreases more, under CIT than under HIT. In this case, both core and headline inflation rates are more deflationary and the negative output gap is wider under CIT than under HIT. From the point of welfare loss, the more contractionary monetary policy causes more welfare loss. Thus, following HIT can incur a lower welfare loss than CIT, when productivity shocks hit the economy.

The situation is different, when the whole union is hit by a negative energy endowment shock. Upon impact, the rising energy price and the nominal stickiness in the non-energy consumption-goods sector result in a higher nominal interest rate under HIT than under CIT. The higher nominal interest rate depresses consumption. The rising energy price reduces the firms' energy input in both countries and pushes the marginal product of labor down. A declining marginal product of labor decreases labor demand, so that households receive less wage payment than before. Upon impact, the decline of household demands for non-energy consumption goods under HIT is greater than under CIT. As a result, the decrease in the outputs of non-energy consumption goods in both countries under HIT is greater than that under CIT. The severe contraction under HIT lowers the demands for both energy good and non-energy consumption goods. Upon impact, both home and foreign inflation rates of non-energy consumption goods fall below zero.

Meanwhile, the increase in the price of the energy good is depressed so that the degree of increase in energy price under HIT is smaller than under CIT. Initially, both headline and core inflation rates under HIT are lower than under CIT. The amplification effect of the monetary policy following HIT yields a wider negative output gap in the whole union. As for the marginal costs, the substantial decline in wage under HIT upon impact counteracts the depressed increase in energy price, and produces a negative real marginal cost gaps in both countries. The previous analysis implies that, by comparison, the slight increase in the nominal interest rate under CIT only causes slight increase in all variables, except for the headline inflation rate in Figure 3. 

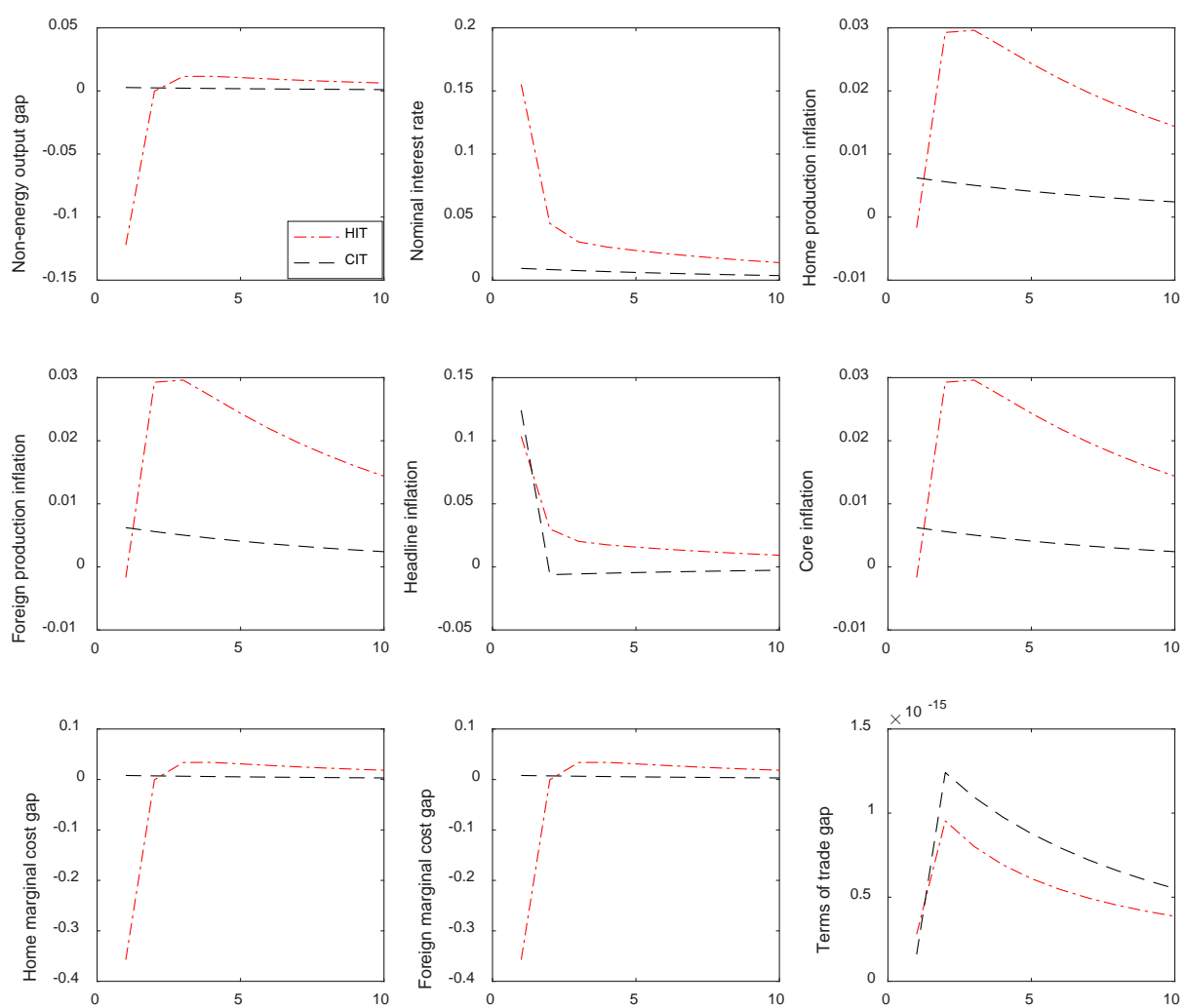

Figure 3: Impulse responses to a negative energy endowment shock

The initial contraction caused by following HIT deflates core inflation and depresses the increase in energy price. Thus, the nominal interest rate under HIT begins to fall to a degree greater than under CIT. Consequently, the economy expands, and the above analysis is in a reversal. At some point in the expansion, the inflation rates of nonenergy consumption goods under HIT in both countries exceed their counterparts under the CIT. The same is therefore also true of both the headline and core inflation rates. The negative output gap in the whole union turns to be positive. Meanwhile, the real marginal cost gaps also change progressively from negative to positive. The monetary policy following HIT amplifies the responses of economy to a negative energy endowment shock, once again. By comparison, by having a mild increase in the nominal interest rate, the CIT avoids the severe contraction and expansion caused by following HIT, thereby incurring a smaller welfare loss. The welfare loss arising from the terms of trade gap is negligible, since the negative energy endowment shock is global for both countries.

To illustrate our analysis, in Table 2 we list the welfare losses by following HIT and 
CIT, respectively, for four alternative cases: (1) $\theta^{H}=\theta^{F}=0.8$, (2) $\theta^{H}=\theta^{F}=0.7$, (3) $\theta^{H}=\theta^{F}=0.6$, and (4) $\theta^{H}=\theta^{F}=0.5$. The welfare loss comparisons in Table 2 confirm our conclusion that, when positive productivity shocks occur, HIT outperforms CIT. Thus, compared with CIT, following HIT yields welfare gains. However, when the whole union is hit by a negative energy endowment shock, it is CIT, rather than HIT, that causes the smaller welfare loss.

Table 2: Welfare losses comparison

\begin{tabular}{lllllll}
\hline & \multicolumn{3}{c}{ Productivity shocks } & \multicolumn{3}{c}{ Energy endowment shock } \\
\cline { 2 - 7 } & HIT & CIT & $\begin{array}{l}\text { Welfare } \\
\text { Gains }\end{array}$ & HIT & CIT & $\begin{array}{l}\text { Welfare } \\
\text { Gains }\end{array}$ \\
\hline $\mathrm{L}\left(\theta^{H}=\theta^{F}=0.8\right)$ & 0.3982 & 0.4172 & 0.0190 & 0.0059 & 0.00018 & 0.0058 \\
$\mathrm{~L}\left(\theta^{H}=\theta^{F}=0.7\right)$ & 0.3010 & 0.3144 & 0.0134 & 0.0035 & 0.00012 & 0.0034 \\
$\mathrm{~L}\left(\theta^{H}=\theta^{F}=0.6\right)$ & 0.2171 & 0.2240 & 0.0070 & 0.0020 & $7.19 \mathrm{e}-05$ & 0.0019 \\
$\mathrm{~L}\left(\theta^{H}=\theta^{F}=0.5\right)$ & 0.1539 & 0.1572 & 0.0033 & 0.0013 & $4.26 \mathrm{e}-05$ & 0.0012 \\
\hline
\end{tabular}

\section{Conclusion}

In this paper, we introduce energy goods into an otherwise standard two-country, monetary union, New Keynesian model to study what is the best inflation measure to target: core inflation or headline inflation. We show that it is impossible to implement the flexible-price equilibrium allocation. To evaluate two alternative Taylor-type monetary policy rules, the headline inflation Taylor rule and the core inflation Taylor rule, we derive the welfare loss function and find that the monetary policymaker should target output gap in the whole union, the terms of trade gap, the Prouder Price Index, and the real marginal cost gaps. We use the welfare loss function as a benchmark to assess two Taylor-type monetary policy rules mentioned above. Welfare loss comparisons reveal that shocks play a very important role in determining which Taylortype monetary policy rule to be chosen by the monetary policymaker. We find that, when positive productivity shocks buffet the economy, following the core inflation Taylor rule amplifies the shock and causes a greater welfare loss than following the 
headline inflation Taylor rule. Thus, the headline inflation Taylor rule is a better choice. By comparison, when a negative energy endowment shock hits the economy, following the headline inflation Taylor rule amplifies the shock and causes a greater welfare loss than following the core inflation Taylor rule. Therefore, the monetary policymaker should follow the core inflation Taylor rule under those circumstances.

\section{REFERENCES}

Anand R., Prasad E., Zhang B.Y., 2015. What measure of inflation should a developing country central bank target? J. Monet. Econ. 74, 102-116.

Aoki, K., 2001. Optimal monetary policy responses to relative-price changes. J. Monet. Econ. 48(1), 55-80.

Bansal, R., Yaron, A., 2004. Risks for the long run: a potential resolution of asset pricing puzzles. J. Finance 59(4), 1481-1509.

Barnett, W. A., 2007. "Multilateral Aggregation-Theoretic Monetary Aggregation over Heterogeneous Countries," Journal of Econometrics, vol 136, no 2, 2007, pp 457482. Reprinted in W. A. Barnett and M. Chauvet (eds.), 2011, Financial Aggregation and Index Number Theory, World Scientific, Singapore, ch. 6.

Barnett, W. A. and Duzhak, E. A., 2010. "Empirical Assessment of Bifurcation Regions within New Keynesian Models," Economic Theory, vol 45, nos 1-2, pp. 99128.

Benigno, P., 2004. Optimal monetary policy in a currency area. J. Int. Econ. 63, 293--320.

Blanchard, O., Gali, J., 2007. Real wage rigidities and the New Keynesian model. J. Money Creidit Bank. 39, 35-65.

Bodenstein, M., Erceg, C.J., Guerrieri, L., 2008. Optimal monetary policy with distinct core and headline inflation rates. J. Monet. Econ. 55, S18--S33.

Calvo, G., 1983. Staggered prices in a utility-maximizing framework. J. Monet. Econ. 12(3), 383-398.

Clarida, R., Gali, J., Gertler, M., 2002. A simple framework for international monetary policy analysis. J. Monet. Econ. 49, 879--904. 
Devereux, M.B., Shi, K., Xu, J., 2010. Oil currency and the dollar standard: a simple analytical model of an international trade currency. J. Money Credit Bank. 42(4), $521-550$.

Erceg, C. J., Henderson, D.W., Levin, A.T., 2000. Optimal monetary policy with staggered wage and price contracts. J. Monet. Econ. 46(2), 281-313.

Farhi, E., Gopinath, G., Itskhoki. O., 2014. Fiscal devaluations. Rev. Econ. Stud. 81, 725-760.

Ferrero, A., 2009. Fiscal and monetary rules for a currency union. J. Int. Econ. 77(1), 1-10.

Gali, J., 2008. Monetary Policy, Inflation, and the Business Cycle: An Introduction to the New Keynesian Framework. Princeton University Press, Princeton.

Gali, J., Monacelli, T., 2005. Monetary policy and exchange rate volatility in a small open economy. Rev. Econ. Stud. 72, 707--734.

Gali, J., Monacelli, T., 2008. Optimal monetary and fiscal policy in a currency union. J. Int. Econ. 76, 116-132.

Gali, J., Monacelli, T., 2016. Understanding the gains from wage flexibility: the exchange rate connection. Am. Econ. Rev. 106(12), 3829-3868.

Gong, L.T., Wang, C., Zou, H.F., 2016. Optimal monetary policy with international trade in intermediate inputs. J. Int. Money. Finance 65:140--165.

Gruber, J., 2006. A tax-based estimate of the elasticity of intertemporal substitution. NBER Working Paper No. 11945.

Hall, R.E., 1988. Intertemporal substitution in consumption. J. Polit. Econ. 96(2), 339-357.

Huang, K., Liu, Z., 2005. Inflation targeting: what inflation rate to target? J. Monet. Econ. 52(8), 1435-1462.

Mankiw, N.G., Reis, R., 2003. What measure of inflation should a central bank target? J. Eur. Econ. Assoc. 1(5), 1058-1086.

Nakamura, E., Steinsson, J., 2014. Fiscal stimulus in a monetary union: evidence from U.S. regions. Am. Econ. Rev. 104(3), 753-792.

Taylor, J.B., 1993. Discretion versus policy rules in practice. J. Monet. Econ. 39, 
195-214.

Woodford, M., 2003. Interest and Prices: Foundations of a Theory of Monetary Policy. Princeton University Press, Princeton.

\section{Appendix:}

\section{A1. Derivation of the steady state}

From the consumption-labor choice equation, we can get

$$
\begin{aligned}
& \Lambda_{H} S_{n}^{\gamma-1} \Psi_{o}^{\alpha}=C^{\sigma}\left(\frac{L^{H}}{\gamma}\right)^{\varphi} \\
& \Lambda_{F} S_{n}^{\gamma} \Psi_{o}^{\alpha}=C^{\sigma}\left(\frac{L^{F}}{1-\gamma}\right)^{\varphi},
\end{aligned}
$$

in which $\Lambda_{H}=\frac{W}{P_{n}^{H}}$ and $\Lambda_{F}=\frac{W}{P_{n}^{F}}$, while $C$ is the steady state consumption of the representative household. In equilibrium, the consumption of the representative household equals the world consumption $C^{W}$. So we have

$$
\frac{\Lambda_{H}}{\Lambda_{F} S_{n}}=\frac{\left(\frac{L^{H}}{\gamma}\right)^{\varphi}}{\left(\frac{L^{F}}{1-\gamma}\right)^{\varphi}}=\left(\frac{(1-\gamma) L^{H}}{\gamma L^{F}}\right)^{\varphi}
$$

From the pricing equation of intermediate goods firms under flexible prices, we have

$$
\begin{aligned}
\left(\Lambda_{H} S_{n}^{\gamma-1} \Psi_{e}\right)^{\delta} & =(1-\delta)^{\delta-1} \delta^{-\delta} \frac{1}{A^{H}} \Lambda_{H} \\
\left(\Lambda_{F} S_{n}^{\gamma} \Psi_{e}\right)^{\delta} & =(1-\delta)^{\delta-1} \delta^{-\delta} \frac{1}{A^{F}} \Lambda_{F} .
\end{aligned}
$$

Note that since we consider efficient steady state under flexible prices, the prices of non-energy goods equal their marginal costs. Then we have

$$
\left(\frac{\Lambda_{H}}{\Lambda_{F} S_{n}}\right)^{\delta}=\frac{\Lambda_{H}}{\Lambda_{F}} .
$$

By rearranging the aggregate production function of the two countries, we get

$$
\begin{gathered}
Y_{n}^{H}=A^{H}\left(L^{H}\right)^{1-\delta}\left(O^{H}\right)^{\delta}=\left(\frac{\delta}{1-\delta}\right)^{\delta} A^{H} L^{H}\left(\Lambda_{H} S_{n}^{\gamma-1} \Psi_{e}\right)^{\delta} \\
Y_{n}^{F}=A^{F}\left(L^{F}\right)^{1-\delta}\left(O^{F}\right)^{\delta}=\left(\frac{\delta}{1-\delta}\right)^{\delta} A^{F} L^{F}\left(\Lambda_{F} S_{n}^{\gamma} \Psi_{e}\right)^{\delta},
\end{gathered}
$$

so that 


$$
\frac{Y_{n}^{H}}{Y_{n}^{F}}=\frac{L^{H}}{L^{F}}\left(\frac{\Lambda_{H}}{\Lambda_{F} S_{n}}\right)^{\delta} .
$$

Combining with the market-clearing condition of the non-energy consumption-goods market,

$$
Y_{n}^{H}=\gamma S_{n}^{1-n} C_{n}^{W}, Y_{n}^{F}=(1-\gamma) S_{n}^{-n} C_{n}^{W},
$$

we obtain

$$
\frac{Y_{n}^{H}}{Y_{n}^{F}}=\frac{\gamma S_{n}}{1-\gamma} .
$$

Therefore

$$
\begin{aligned}
\frac{L^{H}}{L^{F}}\left(\frac{\Lambda_{H}}{\Lambda_{F} S_{n}}\right)^{\delta} & =\frac{L^{H}}{L^{F}} \frac{\Lambda_{H}}{\Lambda_{F}}=\frac{\gamma S_{n}}{1-\gamma} \\
& \Rightarrow \frac{L^{H}}{L^{F}} \frac{\Lambda_{H}}{\Lambda_{F} S_{n}}=\frac{L^{H}}{L^{F}}\left(\frac{(1-\gamma) L^{H}}{\gamma L^{F}}\right)^{\varphi}=\frac{\gamma}{1-\gamma} .
\end{aligned}
$$

From this expression, we have

$$
\frac{L^{H}}{L^{F}}=\frac{\gamma}{1-\gamma} .
$$

Then we can obtain

$$
\frac{\Lambda_{H}}{\Lambda_{F} S_{n}}=\frac{\Lambda_{H}}{\Lambda_{F}}=1, S_{n}=1, \frac{O^{H}}{O^{F}}=\frac{\gamma}{1-\gamma},
$$

since

$$
O^{s}=O^{H}+O^{F}+C_{e}, O_{p}=O^{H}+O^{F}
$$

and

$$
O^{H}=\frac{\delta}{1-\delta} \Lambda_{H} S_{n}^{\gamma-1} \Psi_{e} L^{H}, O^{F}=\frac{\delta}{1-\delta} \Lambda_{F} S_{n}^{\gamma} \Psi_{e} L^{F}
$$

Eliminating $L^{H}$ and $L^{F}$, we obtain

$$
O^{H}=\gamma\left(\frac{\delta}{1-\delta}\right)^{1-\delta}\left(\Lambda_{H} \Psi_{e}\right)^{1-\delta} C_{n}^{W}, O^{F}=(1-\gamma)\left(\frac{\delta}{1-\delta}\right)^{1-\delta}\left(\Lambda_{F} \Psi_{e}\right)^{1-\delta} C_{n}^{W},
$$

so that

$$
O_{p}=\left(\frac{\delta}{1-\delta}\right)^{1-\delta}\left(\Lambda_{H} \Psi_{e}\right)^{1-\delta} C_{n}^{W}
$$

Also, we know that

$$
C_{n}^{W}=\frac{\alpha}{1-\alpha} \Psi_{e} C_{n}^{W}
$$

Therefore, we have the following: 


$$
\begin{aligned}
\frac{O_{p}}{O_{p}+C_{e}} & =\frac{\left(\frac{\delta}{1-\delta}\right)^{1-\delta}\left(\Lambda_{H} \Psi_{e}\right)^{1-\delta} C_{n}^{W}}{\left(\frac{\delta}{1-\delta}\right)^{1-\delta}\left(\Lambda_{H} \Psi_{e}\right)^{1-\delta} C_{n}^{W}+\frac{\alpha}{1-\alpha} \Psi_{e} C_{n}^{W}} \\
& =\frac{\left(\frac{\delta}{1-\delta}\right)^{1-\delta}\left(\Lambda_{H} \Psi_{e}\right)^{1-\delta}}{\left(\frac{\delta}{1-\delta}\right)^{1-\delta}\left(\Lambda_{H} \Psi_{e}\right)^{1-\delta}+\frac{\alpha}{1-\alpha} \Psi_{e}} \\
& =\frac{\left(\frac{\delta}{1-\delta}\right)^{1-\delta} \Psi_{e}}{\left(\frac{\delta}{1-\delta}\right)^{1-\delta} \Psi_{e}+\frac{\alpha}{1-\alpha}(1-\delta)^{\delta-1} \delta^{-\delta} \Psi_{e}} \\
& =\frac{\delta(1-\alpha)}{\alpha+\delta(1-\alpha)},
\end{aligned}
$$

in which the third equality of the above equation comes from the fact that

$$
\left(\Lambda_{H} \Psi_{e}\right)^{\delta}=(1-\delta)^{\delta-1} \delta^{-\delta} \Lambda_{H} \Rightarrow\left(\Lambda_{H}\right)^{\delta-1} \Psi_{e}^{\delta}=(1-\delta)^{\delta-1} \delta^{-\delta} .
$$

So we can get

$$
\frac{C_{e}}{O^{s}}=\frac{\alpha}{\alpha+\delta(1-\alpha)}, \frac{O_{p}}{O^{s}}=\frac{\delta(1-\alpha)}{\alpha+\delta(1-\alpha)} .
$$

This is an important expression for log-linearization of the equilibrium system under sticky price and for derivation of the welfare loss function.

We define the total labor in the whole union as $L=L^{H}+L^{F}$. From $O^{H}=\frac{\delta}{1-\delta} \Lambda_{H} \Psi_{e} L^{H}, O^{F}=\frac{\delta}{1-\delta} \Lambda_{F} \Psi_{e} L^{F}$ and using the fact that $\Lambda_{H}=\Lambda_{F}$, we have

$$
O_{p}=O^{H}+O^{F}=\frac{\delta}{1-\delta} \Lambda_{H} \Psi_{e} L
$$

Meanwhile, $C_{e}=\alpha \Psi_{e}^{1-\alpha} C$. After some algebra, we get

$$
O_{p}=\frac{\delta(1-\alpha)}{\alpha} \alpha \Psi_{e}^{1-\alpha} C=\frac{\delta}{1-\delta} \Lambda_{H} \Psi_{e} L
$$

Combining with $\Lambda_{H} \Psi_{e}^{\alpha}=C^{\alpha} L^{\varphi}$, we can derive the following expression

$$
\begin{aligned}
-\frac{U_{L}(C, L) L}{U_{c}(C, L) C} & =\frac{L^{1+\varphi}}{C^{1-\sigma}} \\
& =(1-\delta)(1-\alpha),
\end{aligned}
$$

which will be used to derive the welfare loss function.

\section{A2 The flexible-price equilibrium}

In the following, we use a lower-case letter, $x_{t}$, to denote the log deviation of the variable 
under sticky price equilibrium from their efficient steady state value. We define $\eta_{H t}=\ln \frac{W_{t}^{H}}{P_{n t}^{H}}-\ln \frac{W^{H}}{P_{n}^{H}}$ and $\eta_{F t}=\ln \frac{W_{t}^{F}}{P_{n t}^{F}}-\ln \frac{W^{F}}{P_{n}^{F}}$. We use $\bar{x}_{t}$ to denote the log deviation of a variable under flexible price equilibrium from its efficient steady state value. We can write $x_{t}=\bar{x}_{t}+\tilde{x}_{t}$, where $\tilde{x}_{t}=x_{t}-\bar{x}_{t}$.

By log-linearizing the labor-consumption choice conditions, the production functions of nonenergy goods, optimal conditions of non-energy firms, the non-energy goods market-clearing conditions, the energy goods market-clearing conditions, the demands of non-energy goods consumption, energy goods consumption, and the definitions of non-energy goods real marginal costs, we obtain the following equations under flexible prices:

$$
\begin{gathered}
\bar{\eta}_{H t}-(1-\gamma) \bar{s}_{n t}+\alpha \bar{\psi}_{e t}=\bar{c}_{t}^{W}+\varphi \bar{l}_{t}^{H} \\
\bar{\eta}_{F t}+\gamma \bar{s}_{n t}+\alpha \bar{\psi}_{e t}=\bar{c}_{t}^{W}+\varphi \bar{l}_{t}{ }^{F} \\
a_{t}^{H}+\delta\left[\bar{\eta}_{H t}-(1-\gamma) \bar{s}_{n t}+\bar{\psi}_{e t}\right]=\bar{\eta}_{H t} \\
a_{t}^{F}+\delta\left[\bar{\eta}_{F t}+\gamma \bar{s}_{n t}+\bar{\psi}_{e t}\right]=\bar{\eta}_{F t} \\
\bar{y}_{n t}^{H}=a_{t}^{H}+\bar{l}_{t}^{H}+\delta\left[\bar{\eta}_{H t}-(1-\gamma) \bar{s}_{n t}+\bar{\psi}_{e t}\right] \\
\bar{y}_{n t}^{F}=a_{t}^{F}+\bar{l}_{t}{ }^{F}+\delta\left[\bar{\eta}_{F t}+\gamma \bar{s}_{n t}+\bar{\psi}_{e t}\right] \\
\bar{y}_{n t}^{H}=(1-\gamma) \bar{s}_{n t}+\bar{c}_{n t}^{W} \\
\bar{y}_{n t}^{F}=-\gamma \bar{s}_{n t}+\bar{c}_{n t}^{W} \\
o_{t}^{s}=\gamma \bar{\eta}_{H t}+(1-\gamma) \bar{\eta}_{F t}+\gamma \bar{l}_{t}^{H}+(1-\gamma) \bar{l}_{t}{ }^{F}+\bar{\psi}_{e t} \\
-\frac{C_{e}}{O^{s}}\left[(1-\delta)\left(\gamma \bar{\eta}_{H t}+(1-\gamma) \bar{\eta}_{F t}\right)-\delta \bar{\psi}_{e t}-\left(\gamma a_{t}^{H}+(1-\gamma) a_{t}^{F}\right)\right] \\
\bar{c}_{n t}^{W}=-\alpha \bar{\psi}_{e t}+\bar{c}_{t}^{W} \\
\bar{c}_{e t}^{W}=\bar{\psi}_{e t}+\bar{c}_{n t}^{W} .
\end{gathered}
$$

The linear system consists of 11 equations and 11 endogenous variables. We can solve for these endogenous flexible-price variables in terms of exogenous shocks $a_{t}^{H}, a_{t}^{F}$, and $o_{t}^{s}$. Specifically, we present the derivation of several important equations: 


$$
\begin{aligned}
& \bar{y}_{n t}^{H}=(1-\gamma) \bar{s}_{n t}+\bar{y}_{n t} \\
&=(1-\gamma)\left(a_{t}^{H}-a_{t}^{F}\right)+\delta o_{t}^{s}+\gamma a_{t}^{H}+(1-\gamma) a_{t}^{F} \\
&= a_{t}^{H}+\delta o_{t}^{s} \\
& \bar{y}_{n t}^{F}=-\gamma \bar{S}_{n t}+\bar{y}_{n t} \\
&=-\gamma\left(a_{t}^{H}-a_{t}^{F}\right)+\delta o_{t}^{s}+\gamma a_{t}^{H}+(1-\gamma) a_{t}^{F} \\
&= a_{t}^{F}+\delta o_{t}^{s} \\
& \bar{s}_{n t}=a_{t}^{H}-a_{t}^{F} \\
& \bar{c}_{t}^{W} \equiv(\alpha+\delta-\delta \alpha) o_{t}^{s}+\gamma(1-\alpha) a_{t}^{H}+(1-\gamma)(1-\alpha) a_{t}^{F} \\
& \bar{\psi}_{e t}=(1-\delta) o_{t}^{s}-\gamma a_{t}^{H}-(1-\gamma) a_{t}^{F} \\
& \bar{c}_{n t}^{W}=\bar{y}_{n t}^{W}=\delta o_{t}^{s}+\gamma a_{t}^{H}+(1-\gamma) a_{t}^{F} .
\end{aligned}
$$

\section{A3 The sticky-price equilibrium}

By log-linearizing the first order conditions, the market-clearing conditions, and some definitions, we obtain the following sticky-price systems. Note that the sticky price system is similar to its flexible price counterpart, except that under flexible prices the prices of the non-energy consumption goods are equal to the mark up of the marginal costs:

$$
\begin{gathered}
\eta_{H t}-(1-\gamma) s_{n t}+\alpha \psi_{e t}=\sigma c_{t}^{W}+\varphi l_{t}^{H} \\
\eta_{F t}+\gamma s_{n t}+\alpha \psi_{e t}=\sigma c_{t}^{W}+\varphi l_{t}^{F} \\
y_{n t}^{H}=a_{t}^{H}+l_{t}^{H}+\delta\left[\eta_{H t}-(1-\gamma) s_{n t}+\psi_{e t}\right] \\
y_{n t}^{F}=a_{t}^{F}+l_{t}^{F}+\delta\left[\eta_{H t}+\gamma s_{n t}+\psi_{e t}\right] \\
y_{n t}^{H}=(1-\gamma) s_{n t}+c_{n t}^{W} \\
y_{n t}^{F}=-\gamma s_{n t}+c_{n t}^{W} \\
o_{t}^{s}=\gamma \eta_{H t}+(1-\gamma) \eta_{F t}+\gamma l_{t}^{H}+(1-\gamma) l_{t}^{F}+\psi_{e t}+\frac{C e}{O s}\left[c_{e t}^{W}-o_{p t}\right] \\
=\gamma \eta_{H t}+(1-\gamma) \eta_{F t}+\gamma l_{t}^{H}+(1-\gamma) l_{t}^{F}+\psi_{e t} \\
-\frac{C e}{O s}\left[(1-\delta)\left(\gamma \eta_{H t}+(1-\gamma) \eta_{F t}\right)-\delta \psi_{e t}-\gamma a_{t}^{H}+(1-\gamma) a_{t}^{F}\right] \\
c_{n t}^{W}=-\alpha \psi \psi_{e t}+c_{t}^{W} \\
\phi_{e t}^{H}=(1-\delta) \eta_{H t}+\delta \psi_{e t}+\delta(1-\gamma) s_{n t}^{W}-a_{t}^{H} \\
\end{gathered}
$$




$$
\phi_{n t}^{F}=(1-\delta) \eta_{F t}-\delta \psi_{e t}-\delta \gamma s_{n t}-a_{t}^{F}
$$

So we obtain 11 equations for 13 endogenous variables (note that $c_{n t}^{W}=y_{n t}^{W}$ ). Since this is a linear system, we can express all variables in terms of non-energy output, $y_{n t}^{W}$, terms of trade, $S_{n t}$, and other exogenous shocks. Especially. We will derive the dynamic IS curve equations and New Keynesian Phillips Curve equations, which are central for characterizing the equilibrium dynamics.

After obtaining the expressions for real marginal costs, $\phi_{n t}^{H}$ and $\phi_{n t}^{F}$, following standard procedures, we have that home and foreign New Keynesian Phillips Curves are, respectively

$$
\pi_{n t}^{H}=\beta \pi_{n t+1}^{H}+\lambda^{H}\left\{\left((1-\delta) A_{c}+\delta \Phi_{c}\right) \tilde{y}_{n t}^{W}+(1-\gamma)\left((1-\delta)\left(1+\frac{\varphi}{1+\delta \varphi}\right)+\delta\right) \tilde{s}_{n t}\right\},
$$

and

$$
\pi_{n t}^{F}=\beta \pi_{n t+1}^{F}+\lambda^{F}\left\{\left((1-\delta) A_{c}+\delta \Phi_{c}\right) \tilde{y}_{n t}^{W}-\gamma\left((1-\delta)\left(1+\frac{\varphi}{1+\delta \varphi}\right)+\delta\right) \tilde{s}_{n t}\right\},
$$

where $(1-\delta) A_{c}+\delta \Phi_{c}=\frac{(\varphi+1)(\alpha(1-\delta)+\delta)}{\alpha\left(\delta^{2}+\delta \varphi+(1-\delta)\right)+(1-\delta) \delta}$.

Log-linearizing the Euler equation of the representative household and rearranging, we can acquire the dynamic IS curve equation

$$
\tilde{y}_{n t}^{W}=E_{t} \tilde{y}_{n t}^{W}-\frac{1}{1-\alpha \Phi_{c}}\left(i_{t}-E_{t} \pi_{t+1}-\bar{r}_{t}\right)
$$

in which $\bar{r}_{t}=\mathrm{E}_{t} \Delta \bar{c}_{t+1}$.

\section{A4 Derivation of the welfare loss function}

We take two steps to derive the second-order approximation to the welfare loss function. First, we take the second-order Taylor expansion for some key equations. Then we use these results to derive the second-order approximation to the joint utility function of the households in the union.

We define

$$
\frac{O_{t}^{s}}{C_{e t}^{W}}=1+\frac{O_{p t}}{C_{e t}^{W}}=\Xi
$$

in which the total energy used in production is $O_{p t}=O_{t}^{H}+O_{t}^{F}$. It follows that

$$
\frac{O_{p t}}{O_{t}^{s}}=\frac{O_{p t}}{C_{e t}^{W}} \frac{C_{e t}^{W}}{O_{t}^{s}}=\frac{O_{p t}}{C_{e t}^{W}} \frac{1}{\Xi}
$$


By log-linearizing, we obtain

$$
o_{p t}=o_{t}^{s}+o_{p t}-c_{e t}^{W}-\xi=o_{t}^{s}+\gamma \tilde{\phi}_{n t}^{H}+(1-\gamma) \tilde{\phi}_{n t}^{F}+\gamma d_{t}^{H}+(1-\gamma) d_{t}^{F}-\xi,
$$

so that

$$
\begin{aligned}
\xi= & \ln \left(1+\frac{O_{p t}}{C_{e t}^{W}}\right) \\
= & \ln \left[1+\omega_{m}\left(e^{\ln \gamma+\tilde{\phi}_{n t}^{H}+d_{t}^{H}}+e^{\ln (1-\gamma)+\tilde{\phi}_{n t}^{F}+d_{t}^{F}}\right)\right] \\
= & \frac{\omega_{m}}{1+\omega_{m}}\left[\left(\gamma \tilde{\phi}_{n t}^{H}+(1-\gamma) \tilde{\phi}_{n t}^{F}\right)+\gamma d_{t}^{H}+(1-\gamma) d_{t}^{F}\right]+\frac{1}{2}\left[\frac{\gamma \omega_{m}}{1+\omega_{m}}-\left(\frac{\gamma \omega_{m}}{1+\omega_{m}}\right)^{2}\right]\left(\tilde{\phi}_{n t}^{H}\right)^{2} \\
& +\frac{1}{2}\left[\frac{(1-\gamma) \omega_{m}}{1+\omega_{m}}-\left(\frac{(1-\gamma) \omega_{m}}{1+\omega_{m}}\right)^{2}\right]\left(\tilde{\phi}_{n t}^{F}\right)^{2},
\end{aligned}
$$

where $\omega_{m}=\frac{\delta(1-\alpha)}{\alpha}, \frac{C_{e}^{W}}{O^{s}}=\frac{1}{1+\omega_{m}}, \frac{O_{p}}{O^{s}}=\frac{\gamma \omega_{m}}{1+\omega_{m}}$.

We can rewrite the above equation as

$$
\begin{aligned}
\xi= & \frac{O_{p}}{O^{s}}\left[\left(\gamma \tilde{\phi}_{n t}^{H}+(1-\gamma) \tilde{\phi}_{n t}^{F}\right)+\gamma d_{t}^{H}+(1-\gamma) d_{t}^{F}\right]+\frac{1}{2}\left[\gamma \frac{O_{p}}{O^{s}}-\gamma^{2}\left(\frac{O_{p}}{O^{s}}\right)^{2}\right]\left(\tilde{\phi}_{n t}^{H}\right)^{2} \\
& +\frac{1}{2}\left[(1-\gamma) \frac{O_{p}}{O^{s}}-(1-\gamma)^{2}\left(\frac{O_{p}}{O^{s}}\right)^{2}\right]\left(\tilde{\phi}_{n t}^{F}\right)^{2},
\end{aligned}
$$

so that

$$
\begin{aligned}
o_{p t}= & o_{t}^{s}+O_{p t}-c_{e t}^{W}-\xi \\
= & o_{t}^{s}+\gamma \tilde{\phi}_{n t}^{H}+(1-\gamma) \tilde{\phi}_{n t}^{F}+\gamma d_{t}^{H}+(1-\gamma) d_{t}^{F}-\xi \\
= & o_{t}^{s}+\frac{C_{e}^{W}}{O^{s}}\left[\gamma \tilde{\phi}_{n t}^{H}+(1-\gamma) \tilde{\phi}_{n t}^{F}+\gamma d_{t}^{H}+(1-\gamma) d_{t}^{F}\right]-\frac{1}{2}\left[\gamma \frac{O_{p}}{O^{s}}-\gamma^{2}\left(\frac{O_{p}}{O^{s}}\right)^{2}\right]\left(\tilde{\phi}_{n t}^{H}\right)^{2} \\
& -\frac{1}{2}\left[(1-\gamma) \frac{O_{p}}{O^{s}}-(1-\gamma)^{2}\left(\frac{O_{p}}{O^{s}}\right)^{2}\right]\left(\tilde{\phi}_{n t}^{F}\right)^{2} .
\end{aligned}
$$

Since

$$
c_{e t}^{W}=o_{t}^{s}-\xi
$$

we have

$$
\begin{aligned}
c_{t}^{W}= & (1-\alpha) y_{n t}^{W}+\alpha\left(o_{t}^{s}-\xi\right) \\
= & (1-\alpha) y_{n t}^{W}+\alpha o_{t}^{s}-\alpha \frac{O_{p}}{O^{s}}\left[\left(\gamma \tilde{\phi}_{n t}^{H}+(1-\gamma) \tilde{\phi}_{n t}^{F}\right)+\gamma d_{t}^{H}+(1-\gamma) d_{t}^{F}\right] \\
& -\frac{\alpha}{2}\left[\gamma \frac{O_{p}}{O^{s}}-\gamma^{2}\left(\frac{O_{p}}{O^{s}}\right)^{2}\right]\left(\tilde{\phi}_{n t}^{H}\right)^{2}-\frac{\alpha}{2}\left[(1-\gamma) \frac{O_{p}}{O^{s}}-(1-\gamma)^{2}\left(\frac{O_{p}}{O^{s}}\right)^{2}\right]\left(\tilde{\phi}_{n t}^{F}\right)^{2}
\end{aligned}
$$

From the aggregate production functions, we know that 


$$
y_{n t}^{H}+d_{t}^{H}=a_{t}^{H}+(1-\delta) l_{t}^{H}+\delta o_{t}^{H}, y_{n t}^{F}+d_{t}^{F}=a_{t}^{F}+(1-\delta) l_{t}^{F}+\delta o_{t}^{F}
$$

In addition, we have

$$
l_{t}^{H}=\frac{1}{1-\delta}\left(y_{n t}^{H}+d_{t}^{H}-\delta o_{t}^{H}-a_{t}^{H}\right), l_{t}^{F}=\frac{1}{1-\delta}\left(y_{n t}^{F}+d_{t}^{F}-\delta o_{t}^{F}-a_{t}^{F}\right),
$$

so that

$$
\begin{aligned}
& \gamma l_{t}^{H}+(1-\gamma) l_{t}^{F}=\frac{1}{1-\delta}\left(\gamma y_{t}^{H}+(1-\gamma) y_{t}^{F}+\gamma d_{t}^{H}+(1-\gamma) d_{t}^{F}-\delta o_{p t}-\left(\gamma a_{t}^{H}+(1-\gamma) a_{t}^{F}\right)\right) \\
& =\frac{1}{1-\delta}\left(y_{n t}^{W}+\gamma d_{t}^{H}+(1-\gamma) d_{t}^{F}-\delta o_{p t}-\left(\gamma a_{t}^{H}+(1-\gamma) a_{t}^{F}\right)\right) \\
& =\frac{1}{1-\delta} y_{n t}^{W}-\frac{\delta}{1-\delta} o_{t}^{s}-\frac{\delta}{1-\delta} \frac{C_{e}}{O^{s}}\left(\gamma \tilde{\phi}_{n t}^{H}+(1-\gamma) \tilde{\phi}_{n t}^{F}\right)+\frac{1}{1-\delta}\left(1-\delta \frac{C_{e}}{O^{s}}\right)\left(\gamma d_{t}^{H}+(1-\gamma) d_{t}^{F}\right) \\
& -\frac{1}{1-\delta}\left(\gamma a_{t}^{H}+(1-\gamma) a_{t}^{F}\right)+\frac{\delta}{2(1-\delta)}\left[\gamma \frac{O_{p}}{O^{s}}-\gamma^{2}\left(\frac{O_{p}}{O^{s}}\right)^{2}\right]\left(\tilde{\phi}_{n t}^{H}\right)^{2}+\frac{\delta}{2(1-\delta)}\left[(1-\gamma) \frac{O_{p}}{O^{s}}-(1-\gamma)^{2}\left(\frac{O_{p}}{O^{s}}\right)^{2}\right]\left(\tilde{\phi}_{n t}^{F}\right)^{2}
\end{aligned}
$$

and

$$
\alpha \frac{O_{p}}{O^{s}}=\frac{\alpha \delta(1-\alpha)}{\alpha+\delta(1-\alpha)}=\delta \frac{C_{e}}{O^{s}}(1-\alpha)=\frac{\alpha \delta(1-\alpha)}{\alpha+\delta(1-\alpha)} .
$$

Thus, we have derived the expressions $c_{t}^{W}$ and $\gamma l_{t}^{H}+(1-\gamma) l_{t}^{F}$, which will be used to eliminate the first order terms in the welfare loss function.

In the following, we assume that $U\left(C^{W}, L\right)=u\left(C^{W}\right)-v(L)=\log C^{W}-\frac{L^{1+\varphi}}{1+\varphi}$.

Since all the households are identical within each region, the total period utility function of the planner is given by

$$
X_{t}=\gamma\left[u\left(C_{t}^{W}\right)-v\left(\frac{L_{t}^{H}}{n}\right)\right]+(1-\gamma)\left[u\left(C_{t}^{W}\right)-v\left(\frac{L_{t}^{F}}{1-\gamma}\right)\right] .
$$

Utility is maximized when consumption and employment take on their efficient values,

$$
X_{t}^{\max }=\gamma\left[\left(u\left(\bar{C}_{t}^{W}\right)-v\left(\frac{\bar{L}_{t}^{H}}{\gamma}\right)\right)\right]+(1-\gamma)\left[\left(u\left(\bar{C}_{t}^{W}\right)-v\left(\frac{\bar{L}_{t}^{F}}{1-\gamma}\right)\right)\right] .
$$

The total welfare loss of the currency union is $\mathbf{W}=\frac{1}{2} E_{0} \sum_{t=0}^{\infty} \beta^{t} w_{t}$, in which $w_{t}=-$ loss $_{t}=\frac{X_{t}-X_{t}^{\max }}{U_{C} C^{W}}$. Taking a second-order approximation around the non-stochastic efficient steady state, we have 
$w_{t}=-\operatorname{loss}_{t}=\tilde{c}_{t}^{W}-(1-\delta)(1-\alpha)\left[\gamma \tilde{l}_{t}^{H}+(1-\gamma) \tilde{l}_{t}^{F}\right]-\frac{1+\varphi}{2}(1-\delta)(1-\alpha)\left\{\gamma\left(\tilde{l}_{t}^{H}\right)^{2}+(1-\gamma)\left(\tilde{l}_{t}^{F}\right)^{2}\right\}$,

in which we use the fact that in steady state $\frac{L^{H}}{\gamma}=\frac{L^{F}}{1-\gamma}=L, u_{C C} C^{W}=-\sigma u_{C} C^{W}$,

$v_{L L} L^{2}=\varphi v_{L} L$, and $\frac{u_{L} L}{u_{C} C^{W}}=(1-\delta)(1-\alpha)$. In addition, note that we use the fact that

$\bar{l}_{t}^{H}=\bar{l}_{t}^{F}=0$, when $\sigma=1$.

Using the expressions for the gaps of $c_{t}^{W}$ and $\gamma l_{t}^{H}+(1-\gamma) l_{t}^{F}$ and substituting them into (31), we obtain the welfare loss function

$$
\begin{aligned}
& w_{t}=- \text { Loss }_{t}=\frac{1-\alpha}{2}\left\{(1+\varphi)(1-\delta)\left(B_{c}^{2}\left(\tilde{y}_{n t}^{W}\right)^{2}+\frac{n(1-n)}{1+\delta \varphi}\left(\tilde{s}_{n t}\right)^{2}\right)\right. \\
& +\frac{\varepsilon \gamma \theta^{H}}{\left(1-\beta \theta^{H}\right)\left(1-\theta^{H}\right)}\left(\pi_{n t}^{H}\right)^{2}+\frac{\varepsilon(1-\gamma) \theta^{F}}{\left(1-\beta \theta^{F}\right)\left(1-\theta^{F}\right)}\left(\pi_{n t}^{F}\right)^{2} \\
& \left.+\frac{\alpha \delta}{\alpha+\delta(1-\alpha)}\left[\gamma-\gamma^{2} \frac{O_{p}}{O^{s}}\right]\left(\tilde{\phi}_{n t}^{H}\right)^{2}+\frac{\alpha \delta}{\alpha+\delta(1-\alpha)}\left[(1-\gamma)-(1-\gamma)^{2} \frac{O_{p}}{O^{s}}\right]\left(\tilde{\phi}_{n t}^{F}\right)^{2}\right\},
\end{aligned}
$$

in which $B_{c}=\frac{a+\delta(1-a)}{a+a \delta \varphi+\delta(1-a)(1-\delta)}$. 